\title{
Skin infections are eliminated by cooperation of the fibrinolytic and innate immune systems
}

\author{
William Santus, ${ }^{1 *}$ Simona Barresi, ${ }^{1}{ }^{*}$ Francesca Mingozzi, ${ }^{1 *}$ Achille Broggi, ${ }^{2 *}$ Ivan Orlandi, ${ }^{1}$ \\ Giulia Stamerra, ${ }^{1}$ Marina Vai, ${ }^{1}$ Alessandra M. Martorana, ${ }^{1}$ Alessandra Polissi, ${ }^{3}$ Julia R. Köhler, ${ }^{4}$ \\ Ningning Liu, ${ }^{4}$ Ivan Zanoni, ${ }^{1,2+\ddagger}$ Francesca Granucci ${ }^{1+\ddagger}$
}

\begin{abstract}
Nuclear factor of activated T cells (NFAT) is activated in innate immune cells downstream of pattern recognition receptors, but little is known about NFAT's functions in innate immunity compared with adaptive immunity. We show that early activation of NFAT balances the two major phases of the innate response to Candida albicans skin infections: the protective containment (abscess) and the elimination (expulsion) phases. During the early containment phase, transforming growth factor- $\beta$ (TGF- $\beta$ ) induces the deposit of collagen around newly recruited polymorphonuclear cells to prevent microbial spreading. During the elimination phase, interferon- $\gamma($ IFN- $\gamma$ ) blocks differentiation of fibroblasts into myofibroblasts by antagonizing TGF- $\beta$ signaling. IFN- $\gamma$ also induces the formation of plasmin that, in turn, promotes abscess capsule digestion and skin ulceration for microbial discharge. NFAT controls innate IFN- $\gamma$ production and microbial expulsion. This cross-talk between the innate immune and the fibrinolytic systems also occurs during infection with Staphylococcus aureus and is a protective response to minimize tissue damage and optimize pathogen elimination.
\end{abstract}

\section{INTRODUCTION}

Nuclear factor of activated T cells (NFAT) proteins form a family of transcription factors that are estimated to have evolved about 500 million years ago, around the same time as the appearance of vertebrates (1). Given the relatively late appearance of NFAT proteins in evolution, their major roles were believed to center on regulation of the adaptive immunity, the more recent form of immunity that appeared with vertebrates. In contrast, innate immunity (the ancient form of immunity) was thought to be controlled primarily by signaling pathways that are conserved during evolution (2), and the prevailing consensus was that NFATs were not involved in this form of immunity (3). However, we and others have shown that the NFAT family can be activated during innate immune responses to bacterial or fungal infections downstream of pattern recognition receptors (4-6).

The NFAT pathway in phagocytes is most effectively activated in response to $\beta$-glucan-bearing fungi (7-9). Fungal infections can develop at a variety of anatomical sites. Although these infections are readily controlled by healthy individuals, they may become systemic in immunocompromised individuals, hospitalized patients, or individuals with inherited mutations in immune genes. Calcineurin is a phosphatase involved in the activation of NFAT transcription factors, and calcineurin inhibitors, such as cyclosporine A (CsA) and tacrolimus, are commonly used as immunosuppressors for treating acute transplant rejection (10), autoimmune diseases (such as psoriasis) (11), and other immunological conditions (such as atopic dermatitis) (12). Although such inhibitors are highly efficient, they

\footnotetext{
'Department of Biotechnology and Biosciences, University of Milano-Bicocca, Piazza della Scienza 2, 20126 Milan, Italy. ${ }^{2}$ Harvard Medical School and Division of Gastroenterology, Hepatology and Nutrition, Boston Children's Hospital, Boston, MA 02115 USA. ${ }^{3}$ Dipartimento di Scienze Farmacologiche e Biomolecolari, Università degli Studi di Milano, Milan, Italy. ${ }^{4}$ Harvard Medical School and Division of Infectious Diseases, Boston Children's Hospital, Boston, MA 02115, USA.

*These authors contributed equally to this work.

tThese authors contributed equally to this work.

fCorresponding author. Email: francesca.granucci@unimib.it (F.G.); ivan.zanoni@ childrens.harvard.edu (I.Z.)
}

have potent side effects that include susceptibility to opportunistic infections from pathogens, such as Candida albicans, Aspergillus fumigatus, and many bacterial species, which are normally well controlled by innate and adaptive immunity $(13,14)$. In principle, CsA and tacrolimus block interleukin-2 (IL-2) and other NFAT-dependent cytokine production by T cells; but increasing evidence supports the notion that susceptibility to microbial infections could mainly arise via inhibition of the NFAT pathway in innate immune cells (6), although the mechanisms that underlie this vulnerability remain elusive.

Here, we have investigated how NFAT activation during innate responses regulates the development and the progress of the inflammatory process induced in the skin by microorganisms and leads to the protection against microbial spreading and, eventually, to microbe elimination.

\section{RESULTS}

\section{NFATC2 is required for the elimination of C. albicans skin} infections by innate immune cells

We first investigated the role of NFATc2 in the innate control of C. albicans infections in the skin. We focused on the study of NFATc2, which is primarily activated in dendritic cells (DCs) and is not expressed in neutrophils, one of the major populations known to fight fungal infections [fig. S1A; (6)]. Thus, in this model, the neutrophil response is not altered [their phagocytic capacity remains unaltered compared to wild-type (WT) neutrophils; fig. S1B], whereas other phagocyte responses may be affected by the absence of NFATc2.

To investigate whether NFATc2 participates in the innate immune responses to fungal infections, we used NFATc2-deficient and WT mice in a model of C. albicans skin infection. Mice were infected in the deep dermis with C. albicans hyphae, and the temporal course of the lesions was evaluated. WT animals displayed skin ulceration at about 2 days after infection (Fig. 1, A and B, and figs. S2 and S3), whereas NFATc2-deficient mice exhibited a capsulated abscess containing C. albicans with no ulceration (Fig. 1, A to C, and 
A

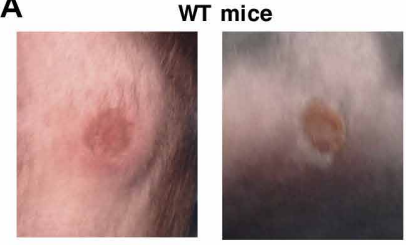

NFATc2-deficient mice

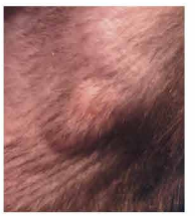

$48 \mathrm{~h}$

B

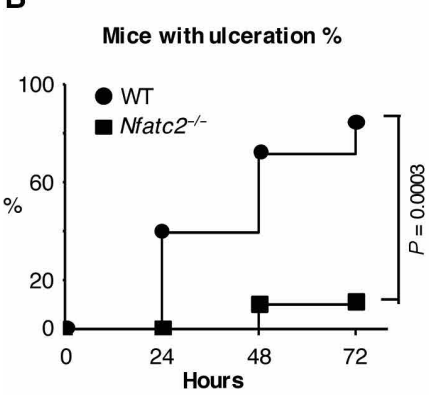

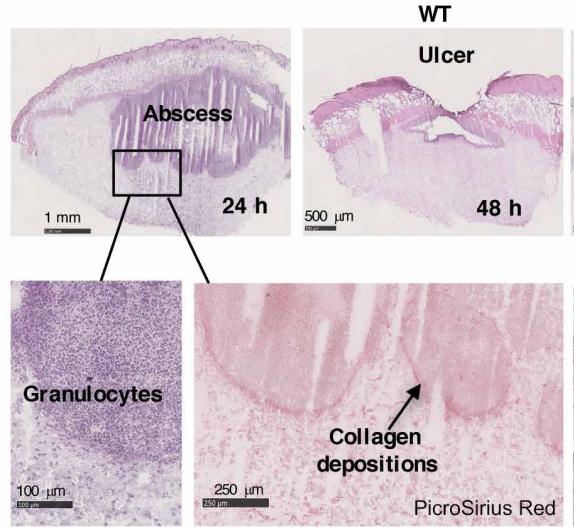

Nfatc2 $^{-/-}$

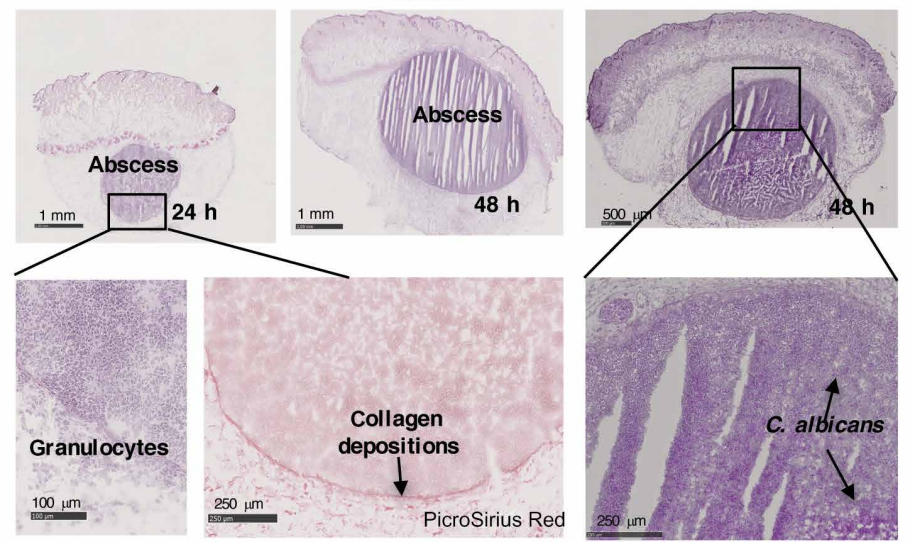

D
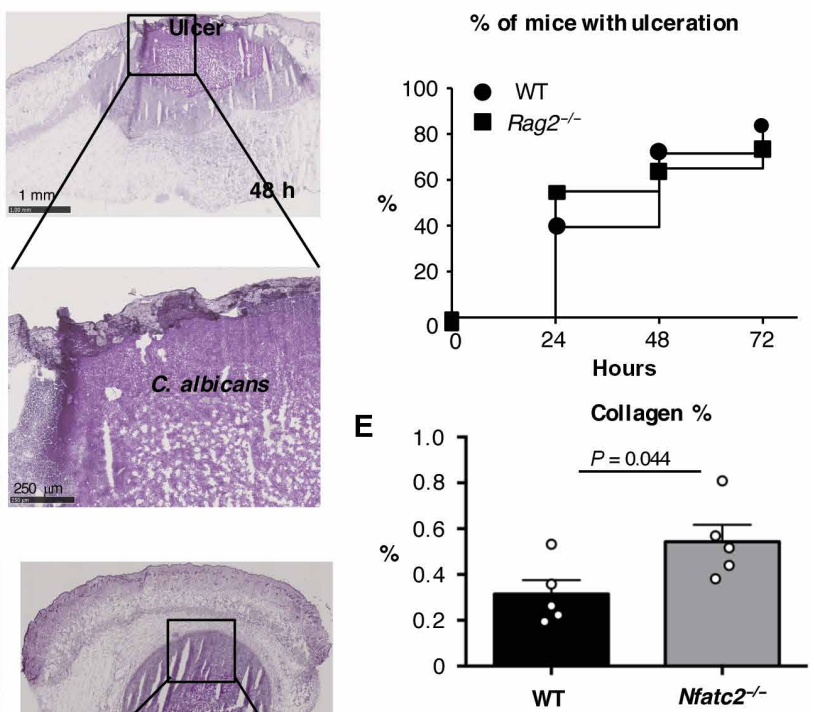

figs. S2 and S3). Although C. albicans could not be eliminated in NFATc2-deficient mice, the infection remained confined in the abscess with no further spreading (fig. S4). The phenotype of the NFATc2-deficient mice was not primarily due to the absence of NFATc2 expression in adaptive immune cells because $\mathrm{Rag}^{-/-}$mice, which lack an adaptive immune system, had a response like that of WT mice (Fig. 1D).

Histological analyses revealed that the abscess was formed by granulocytes recruited to the site of the C. albicans infection, suggesting that recruitment was unchanged between WT and NFATc2deficient mice (Fig. 1C and figs. S2 and S3). Use of quantitative reverse transcription polymerase chain reaction (qRT-PCR) to characterize other cell types recruited to the infection site showed that neutrophils, eosinophils, and basophils were present in both animal types (fig. S5). Monocytes were also recruited in both groups (fig. S5). Although a few differences in the composition of the infiltrate were measurable at specific time points (more eosinophils were recruited in WT mice, and more basophils were recruited in NFATc2-deficient mice), the capacity of WT and NFATc2-deficient animals to recruit immune cells was very similar.

Histological analyses of WT mice also showed that the abscess was surrounded by collagen deposits (Fig. 1, C and E, and figs. S2B and S3). Starting at 48 hours after infection, abscess formation was followed by skin ulceration and the discharge of dead cells and C. albicans from the skin (Fig. 1C and fig. S3). Complete elimination of C. albicans in WT mice occurred in about 6 to 7 days after infection (fig. S6), whereas C. albicans persisted inside the abscess in NFATc2-deficient mice (fig. S6). However, infected skin in NFATc2-deficient mice showed the formation of an abscess surrounded by a well-organized thick collagen capsule (Fig. 1C and figs. S2B and S3), with C. albicans contained inside the abscess (Fig. 1C and figs. S3 and S6). A quantification of collagen deposits around the abscess 24 hours after infection showed significantly less collagen deposit in WT compared with NFATc2 mice (Fig. 1E). 
Fibroblasts surrounded the newly recruited granulocytes in both WT and NFATc2-deficient mice (Fig. 2A). Nevertheless, over time, in NFATc2-deficient but not WT mice, fibroblasts differentiated into myofibroblasts, as indicated by the expression of the $\alpha$-smooth muscle actin ( $\alpha$-SMA) marker (Fig. $2 B$ and fig. S7). These data indicate that WT animals contain and eliminate $C$. albicans skin infections, whereas NFATc2-deficient mice restrain the infection by forming a thick capsule around the abscess but are not able to eliminate the microorganism.

\section{Transforming growth factor- $\beta$ is required for the initial phase of infection containment by promoting fibrosis and is overactive in NFATC2-deficient mice}

The response that we observed in NFATc2-deficient mice had a prominent fibrotic component. Because the transforming growth factor- $\beta$ (TGF- $\beta$ ) is a well-known profibrotic factor (15), we hypothesized that an overactivation of the TGF- $\beta$ pathway was responsible for the behavior of mutant mice. To test this possibility, we examined the activation of the TGF- $\beta$ transduction pathway in WT and NFATc2-deficient mice, evaluating the presence of phosphorylated SMAD2,3 proteins both histologically and by Western blot analysis. As shown in Fig. 3A, the TGF- $\beta$ pathway was activated in both strains; however, the activation was three to four times more pronounced in NFATc2-deficient mice relative to WT mice. In addition, in the histologic evaluation, phosphorylated SMAD2,3 staining was more pronounced in sections from NFATc2-deficient mice (Fig. 3B and fig. S8).

Mice were next treated with an inhibitor of the TGF- $\beta$ transduction pathway (SB-431542) to investigate whether TGF- $\beta$ inhibition could restore the WT phenotype. Therefore, the effect of the inhibitor on the formation of the encapsulated abscess was analyzed after C. albicans infection. We observed that, in response to the reduced activation of the TGF- $\beta$ pathway, both WT and NFATc2-deficient mouse responses were affected. C. albicans was not contained and instead diffused into the subcutaneous space; this led to multiple granulocyte accumulations in both WT and NFATc2-deficient mice (Fig. 3C). Accordingly, the formation of nonorganized collagen deposits around the abscesses was observed in both mouse groups (Fig. 3D and figs. S9 and S10). Overall, these data suggest that the incapability to form adequate collagen capsules when the TGF- $\beta$ pathway was down-modulated was responsible for the reduced containment of the infection.

These data demonstrate that the TGF- $\beta$ pathway activation is required during the initial phase of the inflammatory process for the proper containment of the infection. However, the pathway is overactive in $\mathrm{Nfatc2}{ }^{-/-}$animals and contributes to the formation of excessive collagen deposits around the abscess. The overactivation of the TGF- $\beta$ pathway only partially explains the phenotype of NFATc2-deficient mice because ulceration was not restored in this group of mice even after TGF- $\beta$ inhibition.

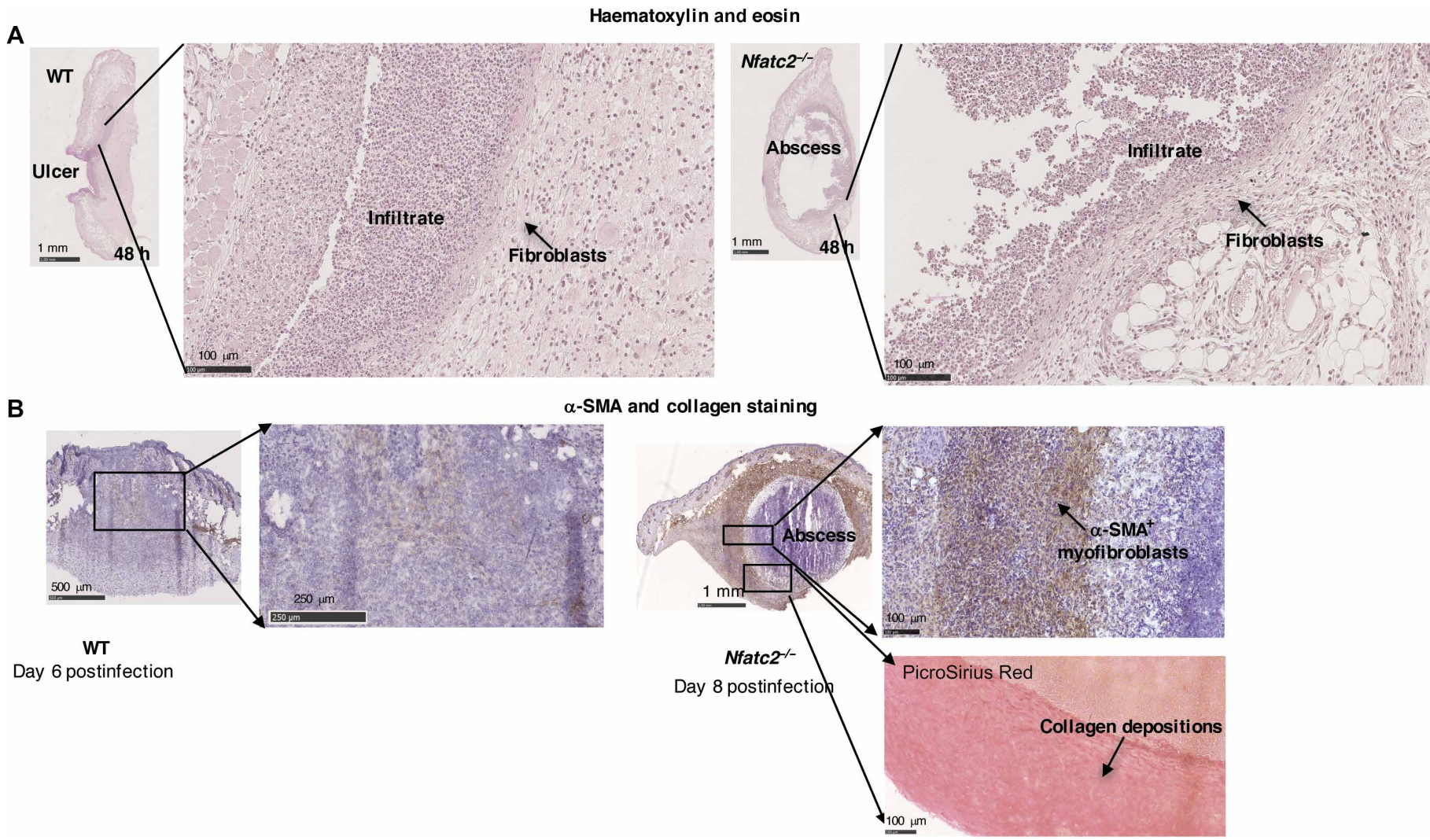

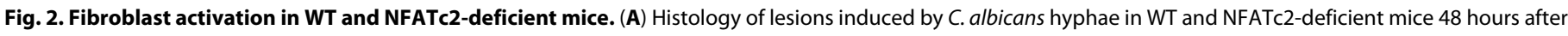

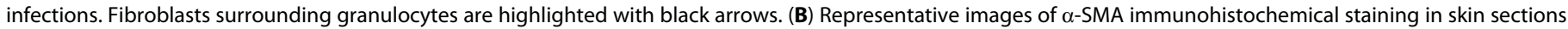

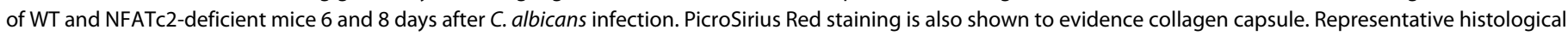
sections of three independent experiments are shown; see also fig. S7. 
A
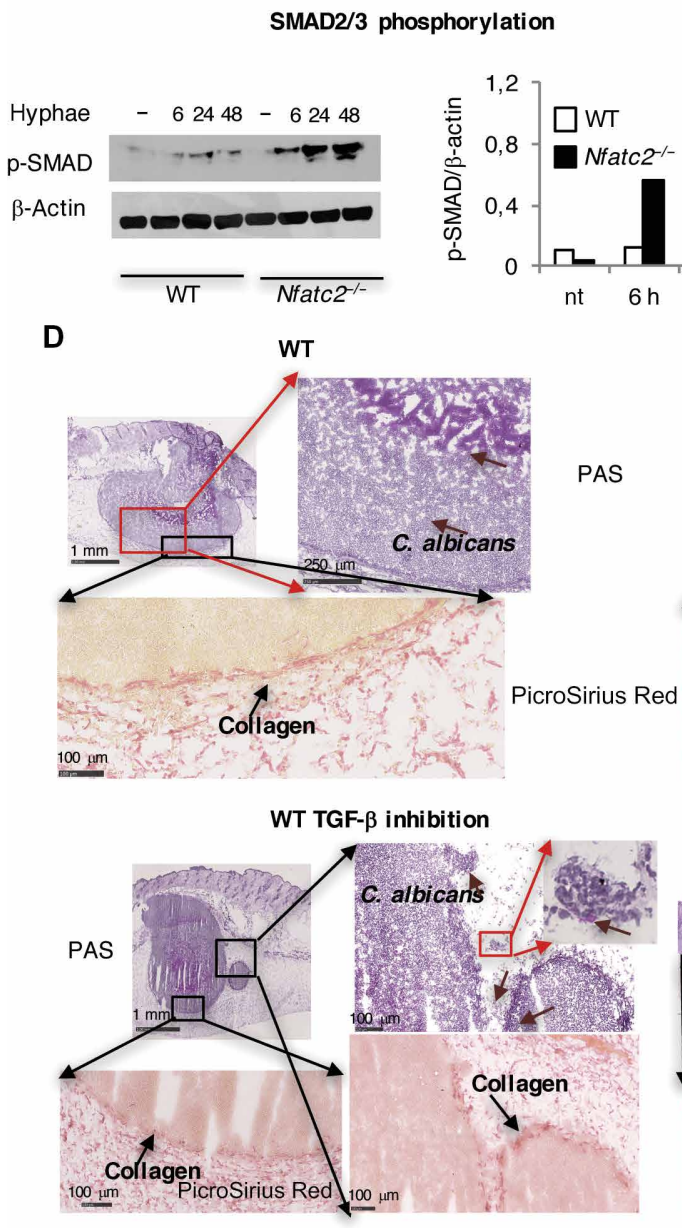

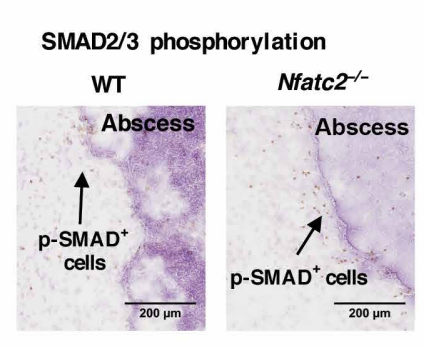

C

$48 \mathrm{~h}$
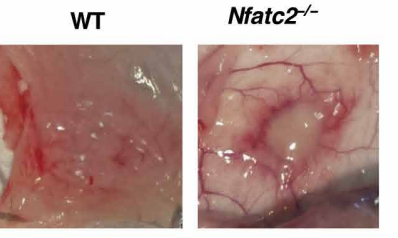

nt
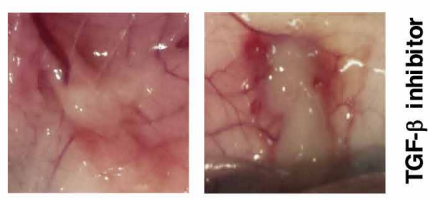
(D) Visualization of C. albicans (purple staining, brown arrows) by PAS staining in WT and NFATc2-deficient mouse skin lesions 24 to 48 hours after C. albicans infections in the presence of TGF- $\beta$ inhibitor. PicroSirius Red staining of selected areas is also shown to evidence collagen depositions (arrows). Note that the collagen capsule is disorganized if the animals are treated with the TGF- $\beta$ inhibitor and C. albicans can exit the abscess (see fig. S6 for higher magnifications). Representative histological sections of three independent experiments are shown; see also fig. S10.

\section{Interferon- $\gamma$ antagonizes TGF- $\beta$ signaling in WT animals}

We next focused on the molecular mechanism that drives the overactivation of the TGF- $\beta$ pathway in NFATc2-deficient mice. In the tissue, TGF- $\beta$ is present in an inactive form and is associated with the extracellular matrix. Various factors, including reactive oxygen species, $\mathrm{pH}$, integrins, and proteases, can induce the release of the active cytokine (16-19). Because the TGF- $\beta$ pathway was activated and required for infection containment in both animal groups (Fig. 3A) but was more active in NFATc2-deficient mice, we hypothesized that active TGF- $\beta$ is released in WT and NFATc2-deficient mice but is then antagonized in WT animals by factors that are produced in an NFATc2-dependent manner. Interferon- $\gamma($ IFN- $\gamma$ ) is a very potent antagonist of TGF- $\beta(20,21)$, and NFATc2-deficient mice were previously described to be prone to develop type 2 responses rather than type $1, \mathrm{IFN}-\gamma$-dependent responses (22). Therefore, we hypothesized that NFATc2-deficient mice showed a deficit in IFN- $\gamma$ production that could explain the differences between the two animal groups. We compared the levels of IFN- $\gamma$ in infected skins from WT and NFATc2-deficient mice. A significant up-regulation of
IFN- $\gamma$ mRNA was observed in WT controls but not in NFATc2deficient mice (Fig. 4A), and more IFN- $\gamma^{+}$cells were found in WT compared with NFATc2-deficient skins by immunohistochemical staining (Fig. 4B and fig. S11). Administration of recombinant IFN- $\gamma$ in NFATc2-deficient mice at the time of C. albicans infection was sufficient to induce ulceration (Fig. 4, C and D), and this correlated with a reduction of the TGF- $\beta$ pathway activation (Fig. 4E). In contrast, when IFN- $\gamma$ was blocked in WT animals, they exhibited the same phenotype of NFATc2-deficient mice, namely, no ulceration (Fig. 4, C and D) and strong activation of the TGF- $\beta$ pathway (Fig. $4 \mathrm{~F}$ ). In accordance with these observations, blocking IFN- $\gamma$ in WT animals favored the formation of a well-organized collagen capsule (Fig. 4D). On the other hand, the exogenous administration of IFN- $\gamma$ to NFATc2-deficient mice hampered the formation of a thick collagen capsule (Fig. 4D). Accordingly, in vitro TGF- $\beta$ promoted skin fibroblast proliferation that was antagonized by IFN- $\gamma$ (Fig. 4G).

IFN- $\gamma$-deficient mice were also analyzed to investigate whether they could recapitulate the phenotype of NFATc2-deficient mice. As expected, IFN- $\gamma$-deficient mice did not undergo ulceration 
A

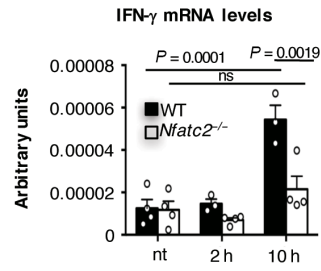

D

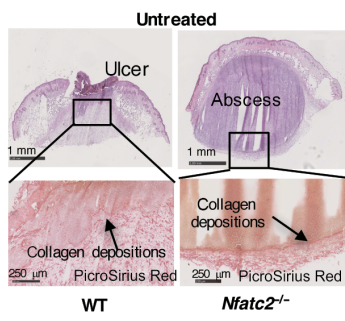

G

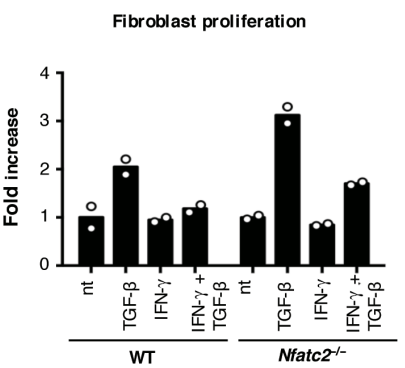

B

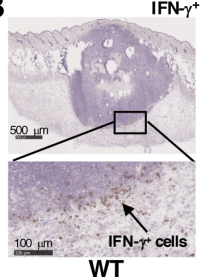

WT
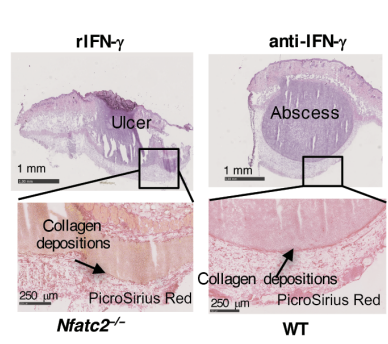

H
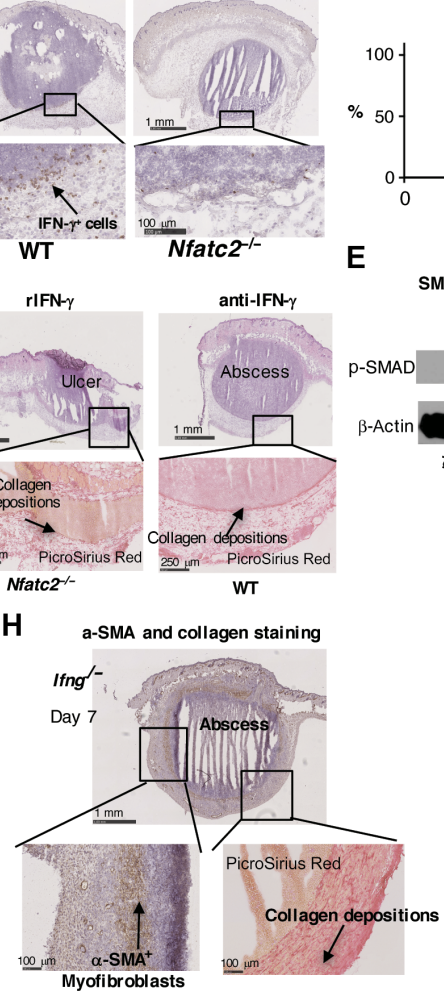

C Mice with ulceration \%

Mice with ulceration \%
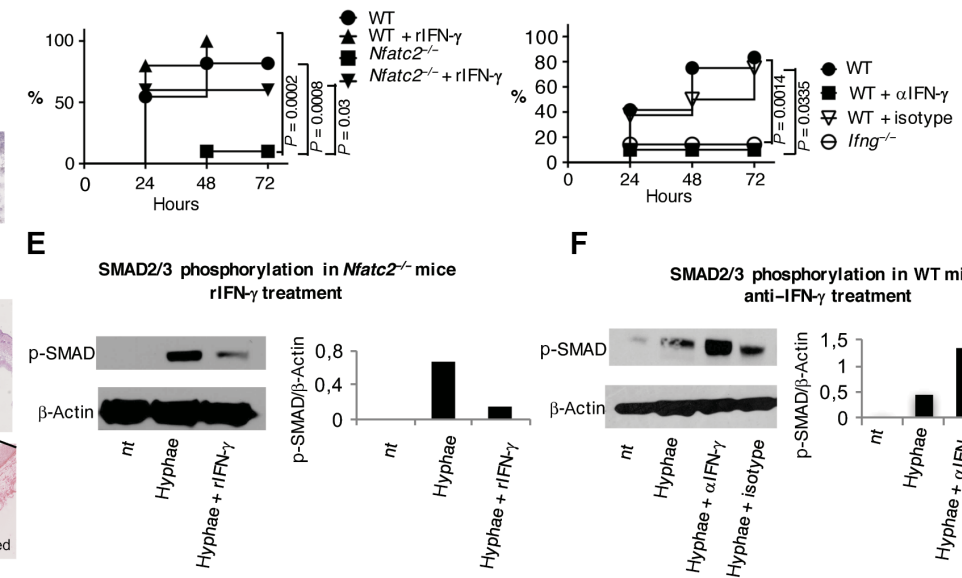

$\mathbf{F}$

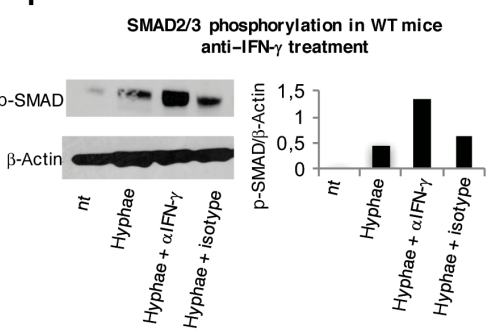

Fig. 4. IFN- $\gamma$ antagonizes TGF- $\boldsymbol{\beta}$ in vivo. (A) qRT-PCR analysis of IFN- $\gamma$ mRNA in C. albicans-infected tissues of WT and NFATC2-deficient mice at the indicated time points after infection; each dot represents a different mouse. Means and SEM are depicted. Statistical significance was determined with a two-way ANOVA. $\mathrm{ns}$, not statistically significant. (B) IFN- $\gamma$ immunohistochemical staining (brown cells) in skin sections 24 hours after C. albicans infection. Representative histological sections from two independent experiments are shown; see also fig. S11. (C) Left: Kaplan-Meier curve showing the percentage of WT and NFATc2-deficient mice undergoing ulceration after $C$. albicans administration in the presence or not of IFN- $\gamma$ at the indicated time points; $n(\mathrm{WT})=11, n(\mathrm{NFATc} 2)=10, n(\mathrm{WT}+$

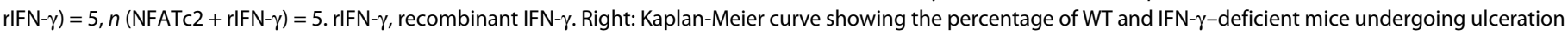

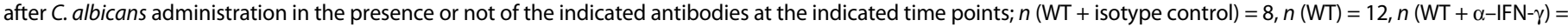

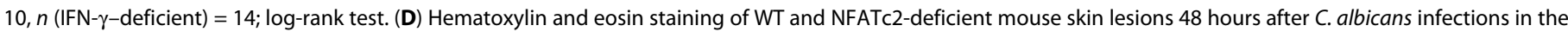

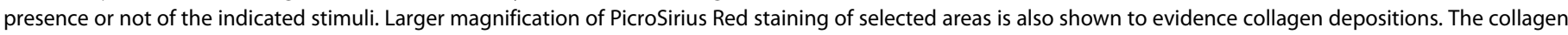

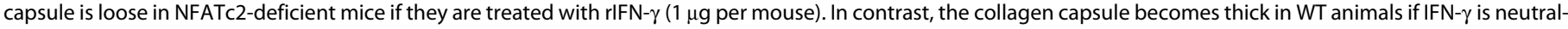

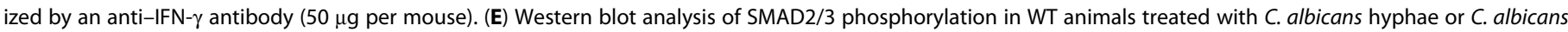

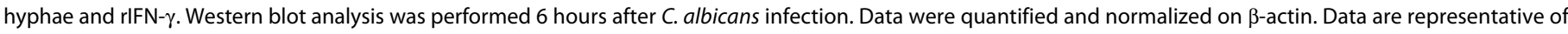

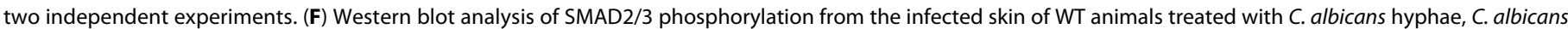

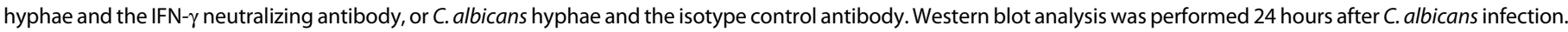

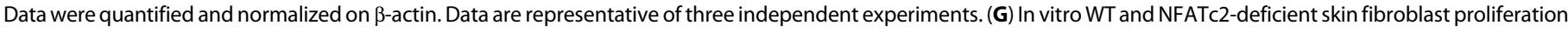

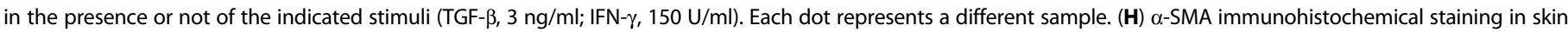
sections of IFN- $\gamma$-deficient mice 7 days after $C$. albicans infection. PicroSirius Red staining is also shown to evidence collagen capsule.

(Fig. 4C) and formed a thick fibroblast and collagen capsule, and fibroblasts differentiated into myofibroblasts (Fig. $4 \mathrm{H}$ ). Overall, our data support a model in which IFN- $\gamma$ controls abscess capsule formation at least in part by antagonizing TGF- $\beta$ signaling.

\section{IFN- $\gamma$ controls collagen capsule degradation by controlling the activation of the fibrinolytic system}

As evidenced above, the pharmacological treatment with IFN- $\gamma$, but not the inhibition of the TGF- $\beta$ pathway, can fully restore the response to $C$. albicans skin infection in NFATc2-deficient mice. These observations imply that the effect of IFN- $\gamma$ cannot be explained with only the antagonistic effect on TGF- $\beta$. Therefore, we predicted that, in addition to TGF- $\beta$ inhibition, IFN- $\gamma$ also contributed to the induction of factors required for capsule degradation and ulceration. This hypothesis was also supported by the observation that the process of capsule disruption in WT animals was further potentiated upon recombinant IFN- $\gamma$ administration (fig. S12). We first focused on factors required for capsule degradation. Under several pathophysiological conditions, a collagen capsule is digested by metalloproteinases that are released by innate immune and stromal cells. Nevertheless, metalloproteinases are released in an inactive form and need to be activated by other proteases, such as plasmin (23-25). To investigate the potential role of plasmin in capsule digestion, we evaluated the levels of active plasmin in the tissue. These were significantly higher in WT compared with NFATc2deficient mice (Fig. 5A).

To confirm plasmin involvement in capsule digestion, we administered plasminogen activator inhibitor-1 (PAI-1) (26), an endogenous inhibitor of plasminogen-to-plasmin conversion, to WT animals to verify whether ulceration could be inhibited. PAI-1 administration initially led to the formation of an encapsulated abscess and no ulceration (Fig. 5, B and C, and fig. S13), confirming that plasmin is required for capsule digestion and ulceration. Nevertheless, at later time points, the abscess did not show the organization exhibited in NFATc2-deficient mice, and no differentiation of fibroblasts in myofibroblasts was observed (Fig. 5D). This was predictable given the presence of IFN- $\gamma$ (which inhibits TGF- $\beta$ ) in the skin of WT animals. 
Plasminogen-to-plasmin conversion is induced by activators of plasminogen, such as tissue plasminogen activator (tPA). We therefore evaluated the presence of $\mathrm{PA}$ in the tissue of infected mice. In line with our prediction, tPA levels were much higher in WT compared with NFATc2-deficient mice (Fig. 5E). We also analyzed the levels of endogenous PAI-1 that inhibits plasmin formation. PAI-1 was also more expressed in WT compared with NFATc2-deficient mice (Fig. 5E). In WT animals, tPA production was induced early, when PAI-1 was not present in the tissue (Fig. 5E). The counterregulation of tPA and PAI-1 observed in WT animals is presumably required to first allow plasmin generation and then avoid excessive plasmin accumulation.
Given that plasmin is required for capsule digestion, we investigated whether IFN- $\gamma$ influenced the activation of the fibrinolytic system. We tested our hypothesis both by administering IFN- $\gamma$ to NFATc2-deficient mice and by blocking IFN- $\gamma$ in WT animals. As expected, adding IFN $-\gamma$ restored $\mathrm{TPA}$ and PAI-1 production in NFATc2-deficient mice (Fig. 5E). On the contrary, blocking IFN- $\gamma$ in WT animals inhibited the release of tPA and PAI-1 (Fig. 5E). This indicates that the entire pathway that leads to plasmin formation is altered by the absence of IFN- $\gamma$ in NFATc2-deficient mice. To further support our conclusions, we also measured active plasmin in the tissue of NFATc2-deficient mice treated or not with IFN- $\gamma$ and of WT animals treated or not with a blocking IFN- $\gamma$ antibody at the time
A

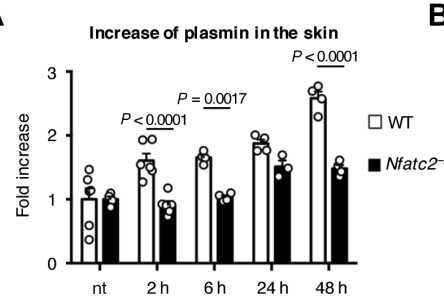

E
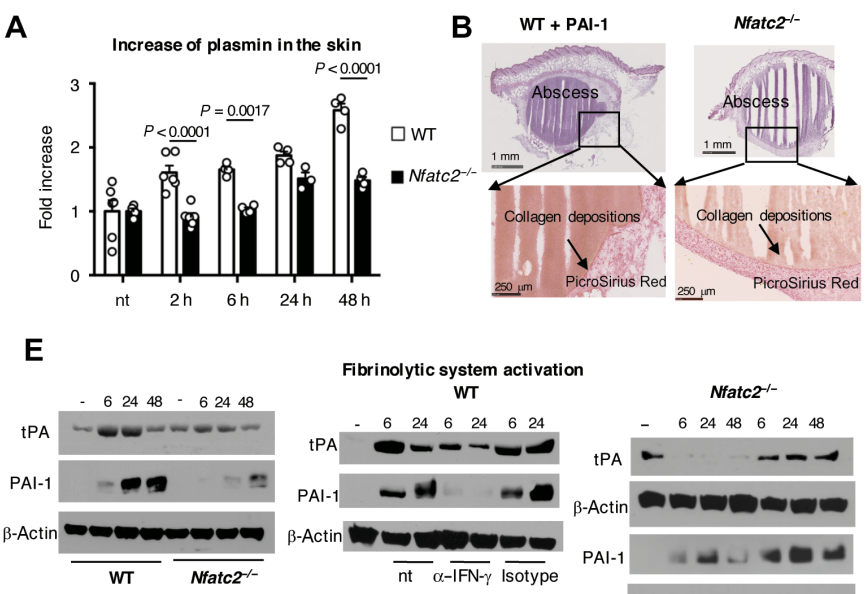

C

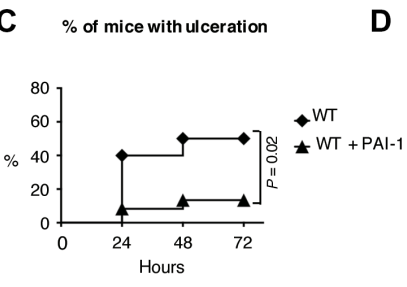

$\mathbf{F}$
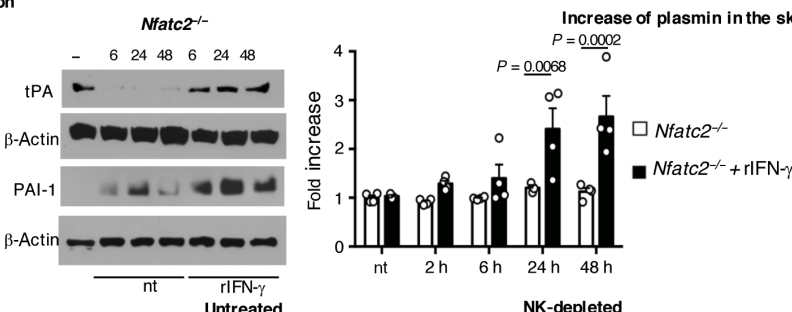

Increase of plasmin in the skin
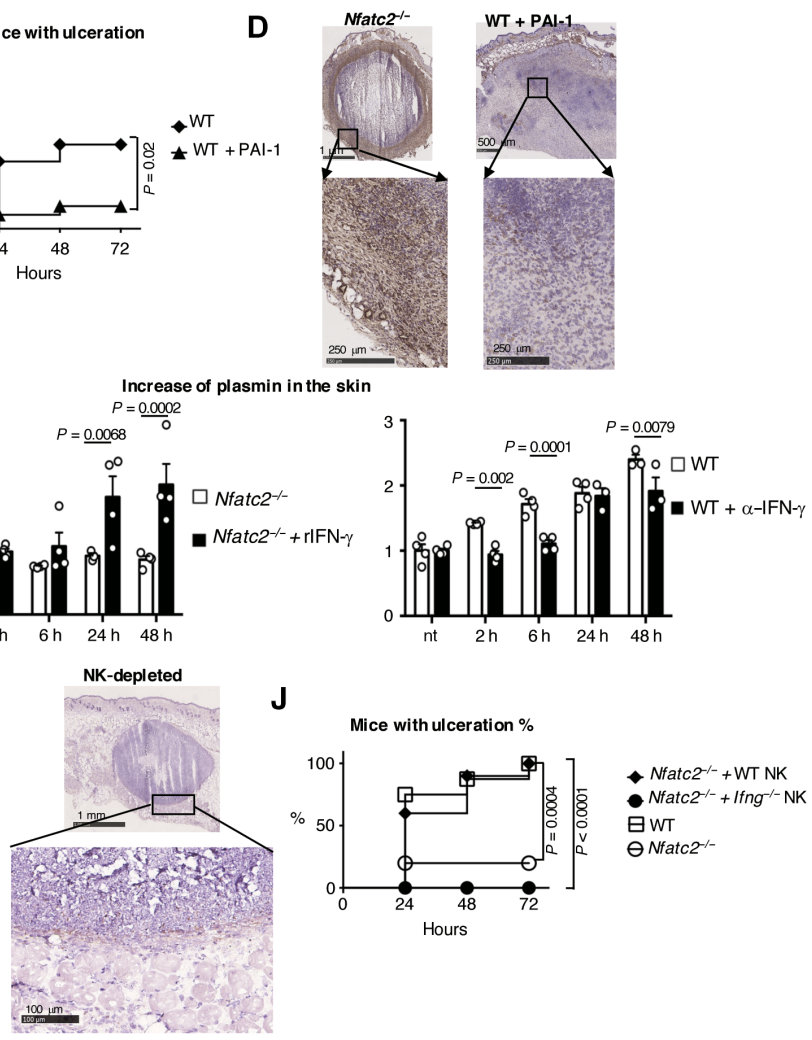

$\mathbf{J}$

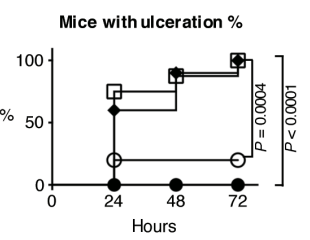

- Nfatc2 $2^{-1-}+$ WT NK $\mathrm{Nfatc2}^{-1-}+$ lfng $^{-1-} \mathrm{NK}$ 日WT Ө Nfatc2--

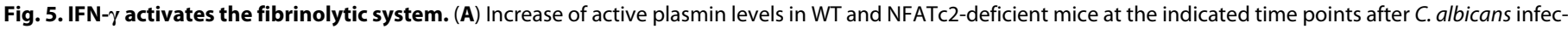

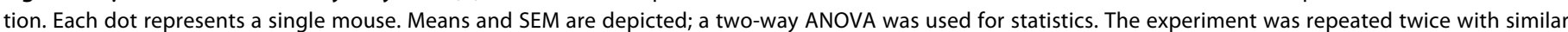

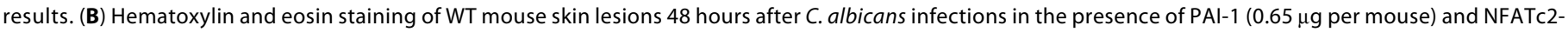

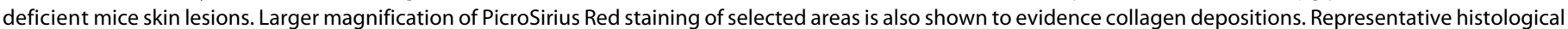

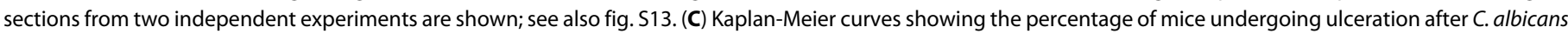

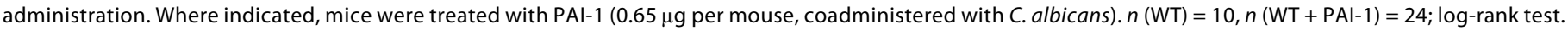

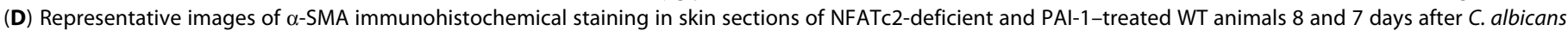

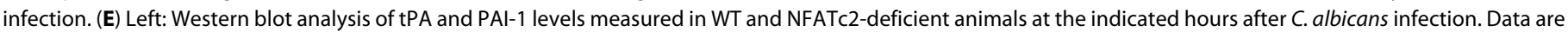

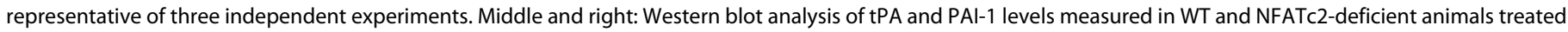

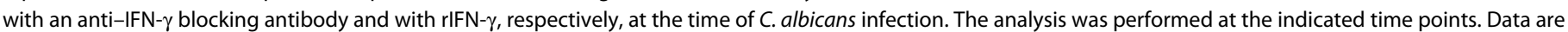

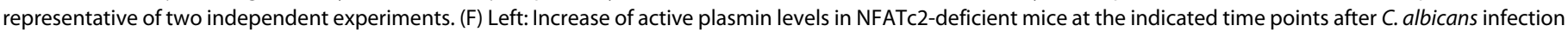

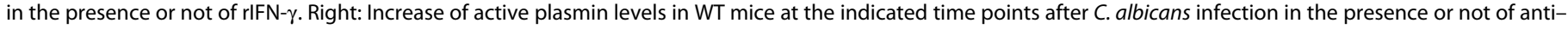

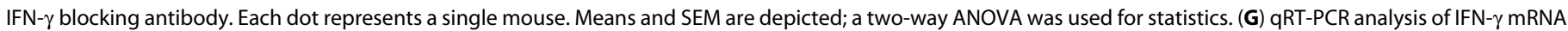

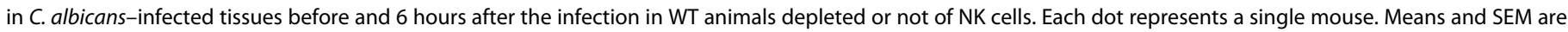

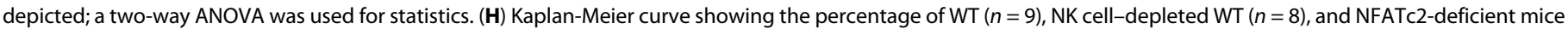

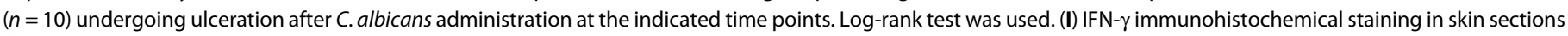

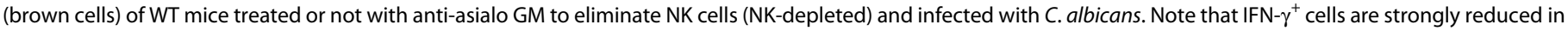

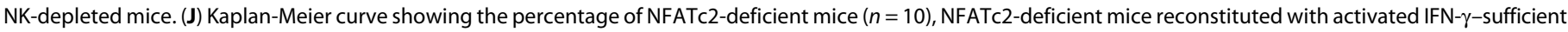

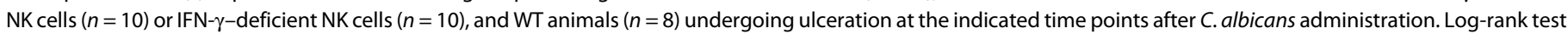
was used. 


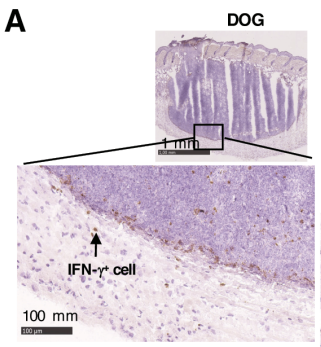

$\mathbf{E}$
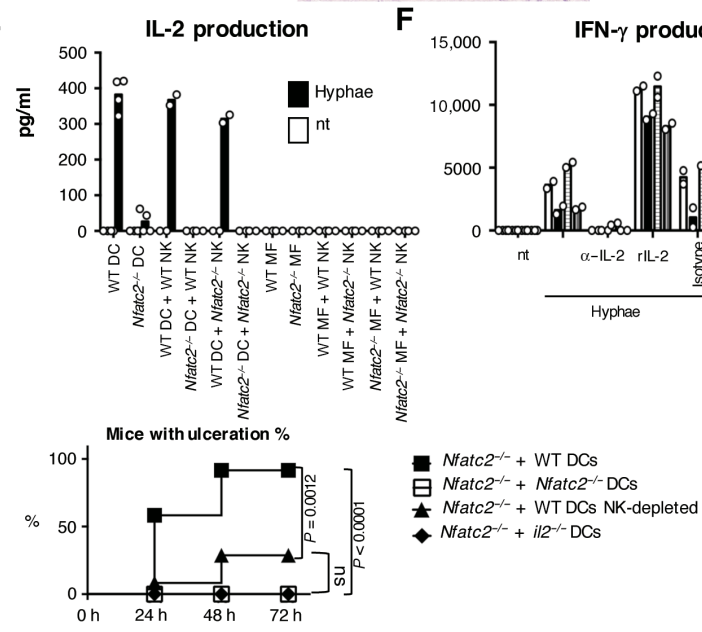

B

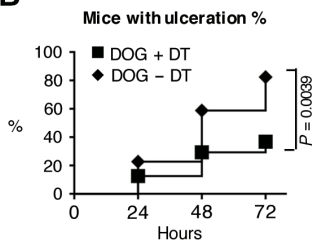

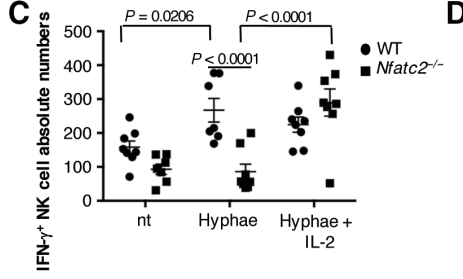

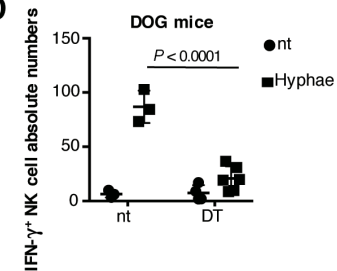

G

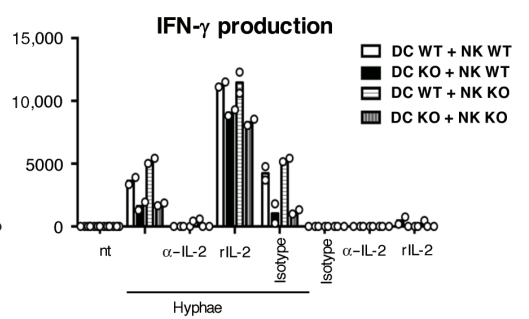

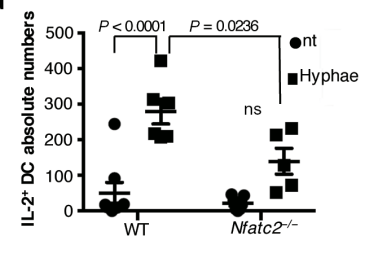

H

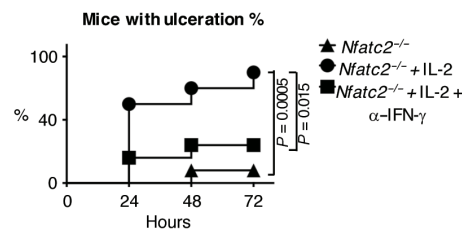

Fig. 6. DCs are required for NK cell activation. (A) IFN- $\gamma$ immunohistochemical staining in skin sections (brown cells) of DOG mice and DC-depleted DOG mice (DOG + DT) after C. albicans infection. Representative histological sections from two independent experiments are shown; see also fig. S19. (B) Kaplan-Meier curve showing the percentage of DC-sufficient $(n=22)$ and DC-depleted $(n=32)$ DOG mice (DOG + DT) undergoing ulceration after C. albicans administration at the indicated time points; log-rank test. (C) Absolute numbers of IFN- $\gamma^{+} \mathrm{NK}$ cells at the draining lymph nodes of WT and NFATc2-deficient mice 4 hours after $C$. albicans infections. Where indicated, mice were cotreated with C. albicans and rIL-2. Each symbol represents a different mouse. Means and SDM are depicted; a two-way ANOVA test was used for statistics. (D) Absolute numbers of IFN- $\gamma^{+}$NK cells at the draining lymph nodes of DOG mice treated or not with DT 4 hours after C. albicans infections. Each symbol represents a different mouse. Means and SDM are depicted; a two-way ANOVA test was used for statistics. (E) IL-2 released in the supernatants by WT or NFATc2-deficient BMDCs and BM macrophages (MF) before and after C. albicans exposure (MOI, 0.05). IL-2 released by DCs-NK cell and macrophages-NK cell cocultures is also shown. Each dot represents a different sample. (F) Immature or C. albicans-activated WT and NFATc2-deficient BMDCs were cultured with NK cells for 18 hours. Where indicated, IL-2 was blocked using the S4B6 anti-IL-2 antibody ( $\alpha-I L-2)$, or rlL-2 was added to the cultures. Levels of IFN- $\gamma$ in the supernatant were then quantified by ELISA. Each dot represents a different sample. Representative data of two independent experiments are shown. KO, knockout. (G) Absolute numbers of IL-2 ${ }^{+}$DCs at the draining lymph nodes of WT and NFATc2-deficient mice 4 hours after $C$. albicans infections. Each symbol represents a different mouse. Means and SDM are depicted; a two-way ANOVA test was used for statistics. (H) Kaplan-Meier curves showing the percentage of NFATc2-deficient mice undergoing ulceration after C. albicans administration in the presence or not of the indicated stimuli and at the indicated time points; $n\left(\mathrm{Nfatc}^{-{ }^{-}-}\right)=10, n\left(\mathrm{Nfatc2^{-/- }}+\mathrm{IL}-2\right)=8$, $n\left(\mathrm{Nfatc2}^{-/-}+\mathrm{IL}-2+\alpha-\mathrm{IFN}-\gamma\right)=10$; log-rank test. (I) Kaplan-Meier curves showing the percentage of NFATc2-deficient mice reconstituted with DCs of the indicated genotype undergoing ulceration after $C$. albicans administration. Where indicated, NK cells were depleted. $n=12$ per group; log-rank test.

of C. albicans administration. As shown in Fig. 5F, IFN- $\gamma$ restored plasmin generation in NFATc2-deficient mice, whereas the inhibition of IFN- $\gamma$ down-modulated plasmin formation in WT animals.

Last, we evaluated the levels and function of activated matrix metalloproteinase-3 (MMP-3) during the infection. We focused on MMP-3 because it is efficiently activated by plasmin and is a master metalloproteinase that activates downstream metalloproteinases, such as MMP-9, and digests extracellular matrix components $(23,27)$. As shown in fig. S14A, the increase of activated MMP-3 during the infection paralleled the increase of plasmin with the same relevant differences during abscess formation. In addition, treatment with an MMP-3 peptide inhibitor (MMP-3 inhibitor I) upon C. albicans administration inhibited ulceration (fig. S14B).

\section{Natural killer cells are the major source of IFN- $\gamma$ in WT animals, and DCs are essential accessory cells for natural killer cell activation during fungal infections}

The next step was to determine the source of IFN- $\gamma$. Because Rag2 ${ }^{-/-}$ mice behaved like WT animals and showed a potent up-regulation of IFN- $\gamma$ mRNA in the skin after infection (Fig. 1D and fig. S15), we excluded a T cell origin for the IFN- $\gamma$ and focused on innate immune cells. Elimination of natural killer (NK) cells by anti-asialo GM treatment strongly affected the levels of IFN- $\gamma$ mRNA, as measured by qRT-PCR (Fig. 5G). Similarly, in the absence of NK cells, ulceration was strongly diminished after C. albicans infection of WT animals (Fig. 5H). Upon NK cell depletion, no IFN- $\gamma^{+}$cells were observed in the infected skins (Fig. 5I). These data confirm that NK cells are the major source of IFN- $\gamma$ in our experimental system.

To formally demonstrate that NK cells are necessary and sufficient to provide IFN- $\gamma$ under our experimental conditions, we first activated in vivo WT and IFN- $\gamma$-deficient NK cells and then adoptively transferred the activated NK cells into NFATc2-deficient mice infected with C. albicans. The course of the infection was then followed over time. After the adoptive transfer of activated WT but not IFN- $\gamma$-deficient NK cells, NFATc2-deficient mice showed ulceration (Fig. 5J). These data confirmed that IFN- $\gamma$ provided by NK cells is necessary and sufficient to induce capsule degradation and ulceration.

Next, we unveiled the connection between NFATc2 and IFN- $\gamma$ production by NK cells. In vitro, we observed that NFATc2 expression in accessory cells (e.g., DCs), but not in NK cells themselves, 

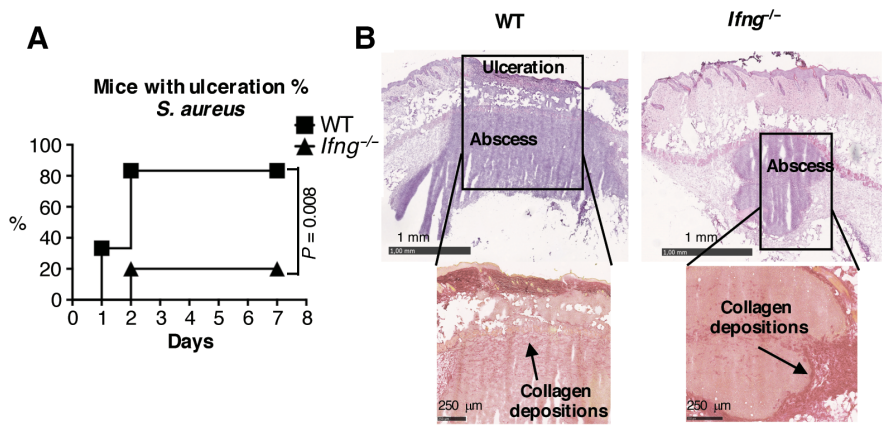

C

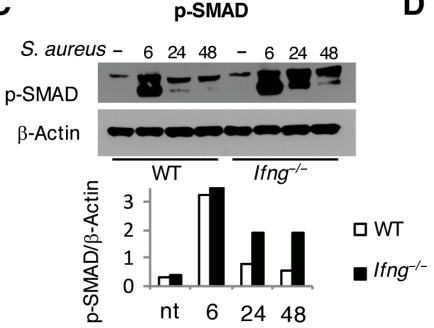

D

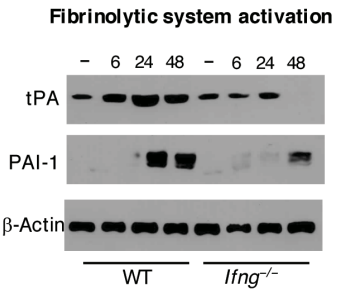

Fig. 7. Innate immune and fibrinolytic systems cooperate also during bacterial infections. (A) Kaplan-Meier curve showing the percentage of WT $(n=6)$ and IFN- $\gamma-$ deficient mice $(n=10)$ undergoing ulceration after $S$. aureus administration at the indicated time points; log-rank test. Representative data of two independent experiments. (B) Hematoxylin and eosin staining of WT and IFN- $\gamma$-deficient mice skin lesions 48 hours after $S$. aureus infection. PicroSirius Red staining is also shown to evidence collagen depositions. (C) Western blot analysis of SMAD2/3 phosphorylation at the indicated time points after $S$. aureus infection of WT and IFN- $\gamma$-deficient mice. Data were quantified and normalized on $\beta$-actin. Data are representative of three independent experiments. (D) Western blot analysis of tPA and PAI-1 levels measured in WT and IFN- $\gamma$-deficient animals at the indicated hours after $S$. aureus infection.

was necessary for the production of IFN- $\gamma$ by NK cells upon C. albicans encounter (fig. S16, A and B). We therefore predicted that eliminating DCs in vivo would influence IFN- $\gamma$ production by NK cells after infection by C. albicans. We thus used B6.Cg-Tg(Itgax-DTR/OVA/ EGFP) $1 \mathrm{Gjh} / \mathrm{Crl}$ (DOG) mice [which express a diphtheria toxin (DT) receptor under the CD11c promoter to eliminate DCs (28)] and studied the course of the infection in the absence of DCs. As we previously showed, DT treatment eliminated DCs from the skin, lymph node, and spleen (fig. S17) (29-31). The recruitment of inflammatory cells was not altered by DC depletion (fig. S18). IFN- $\gamma^{+}$cells were strongly diminished in DC-deficient mice infected skins compared with DC-sufficient mice, as revealed by immunohistochemistry (Fig. 6A and fig. S19). Accordingly, as depicted in Fig. 6B, the number of animals undergoing ulceration was significantly reduced. This finding suggests that DCs are required to elicit IFN- $\gamma$ production by NK cells after $C$. albicans infection. In keeping with this observation, IFN- $\gamma^{+}$ NK cells were strongly diminished in the lymph nodes of NFATc2-deficient and DC-deficient mice after infection, compared with control animals (Fig. 6, C and D).

We then determined why NFATc2-deficient DCs are not able to activate NK cells. Two cytokines involved in NK cell activation, namely, IL-12 and IL-2, were described to be produced in an NFAT-dependent manner by DCs in response to zymosan (5). We first measured IL-12p70 production by DCs after C. albicans hyphae infection, but, although it was previously shown to be induced in DCs upon zymosan administration, we found no IL-12 production in response to the $C$. albicans hyphae challenge (fig. S20). We therefore focused on IL-2, described to be strongly induced in DCs during C. albicans hyphae infections as well (32-34) and also described to be necessary for eliciting IFN- $\gamma$ production by NK cells during bacterial infections $(30,35)$. Figure 6 (E and F) shows that DC-derived IL-2 is required for NK cell activation in the presence of C. albicans in vitro and that NFATc2-deficient DCs were unable to activate NK cells because they do not produce IL-2. We thus evaluated the presence of IL- ${ }^{+}$DCs in the lymph nodes of WT and NFATc2-deficient mice after C. albicans administration. Whereas the numbers of DCs that produce IL-2 were strongly increased in WT animals after infection, no induction of IL-2 production by DCs was detected in NFATc2-deficient mice (Fig. 6G). Accordingly, in vivo IL-2 administration to NFATc2-deficient mice at the time of C. albicans infection restored NK cell activation (Fig. 6C). Moreover, after IL-2 administration, NFATc2-deficient mice presented ulceration (Fig. 6H). The restoration of ulcer formation in NFATc2-deficient mice upon IL-2 administration was inhibited when a blocking antiIFN- $\gamma$ antibody was also administered (Fig. $6 \mathrm{H}$ ). These data demonstrate that after C. albicans infection, NFATc2-deficient DCs do not produce IL- 2 and, consequently, do not induce IFN- $\gamma$ release by NK cells.

To test whether DC-derived IL-2, produced in an NFATc2depedent manner in response to $C$. albicans administration, was necessary and sufficient to induce ulceration, we performed the following experiment. NFATc2-deficient mice were adoptively transferred with WT, NFATc2-deficient, and IL-2-deficient DCs at the time of $C$. albicans administration, and the course of the infection was analyzed. As depicted in Fig. 6I, only mice that received WT DCs showed ulceration. Moreover, if NK cells were eliminated after the administration of WT DCs, ulceration was prevented (Fig. 6I).

Collectively, these data indicate that activation of NFATc2 in DCs during fungal infection regulates IL-2 production, which then elicits IFN- $\gamma$ production by NK cells. In turn, IFN- $\gamma$ is necessary for counteracting the TGF- $\beta$ pathway and for allowing plasmin formation, collagen capsule digestion, and C. albicans expulsion.

\section{IFN- $\gamma$ antagonizes TGF- $\beta$ signaling and allows abscess elimination through the activation of the fibrinolytic systems also during Staphylococcus aureus infections}

Last, we investigated whether the cross-talk between the fibrinolytic and the innate immune systems, which regulates the persistence of the encapsulated abscess and the elimination of the microbes, applies not only to fungal but also to bacterial infections. Mice were infected with the Gram-positive bacterium $S$. aureus, which can infect the skin and form abscess. As shown in Fig. 7 (A and B), the infection induced skin ulceration in WT animals, whereas an encapsulated abscess formed in IFN- $\gamma$-deficient mice. As with $C$. albicans infections, excessive activation of the TGF- $\beta$ pathway and overproduction of tPA and PAI- 1 in WT with respect to IFN- $\boldsymbol{\gamma}$-deficient mice were observed (Fig. 7, C and D). This indicates that also during bacterial infections, IFN- $\gamma$ can induce the activation of the fibrinolytic system to favor microbial elimination.

\section{DISCUSSION}

In this study, we report two phases of the inflammatory response elicited by microbial infections of the skin. The first is the phase of infection containment. In this phase, granulocytes and fibroblasts 


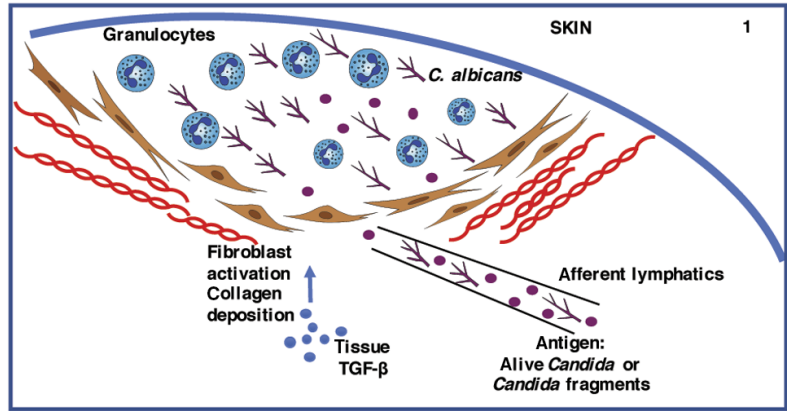

Infection containment: Late phase

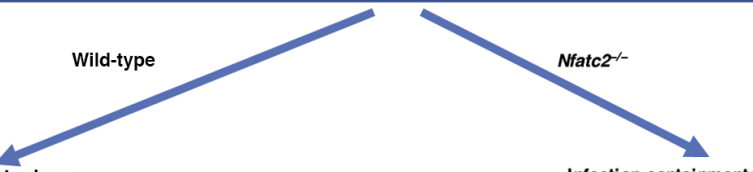

Infection containment: Late phase

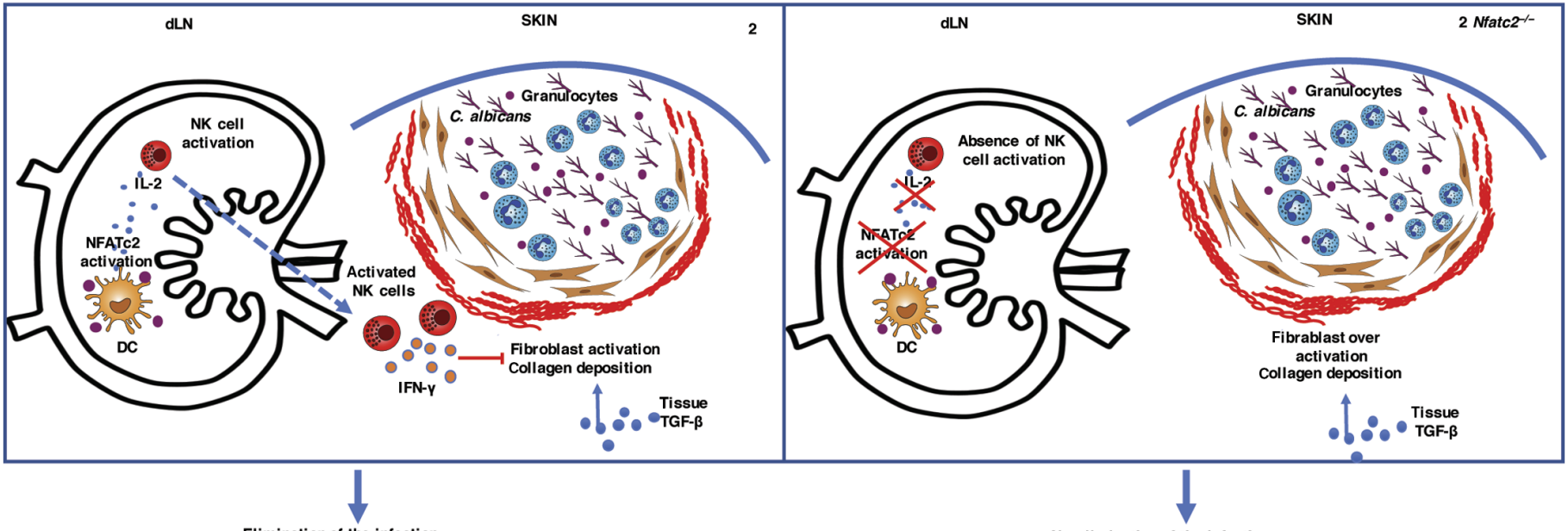

Elimination of the infection

No elimination of the infection

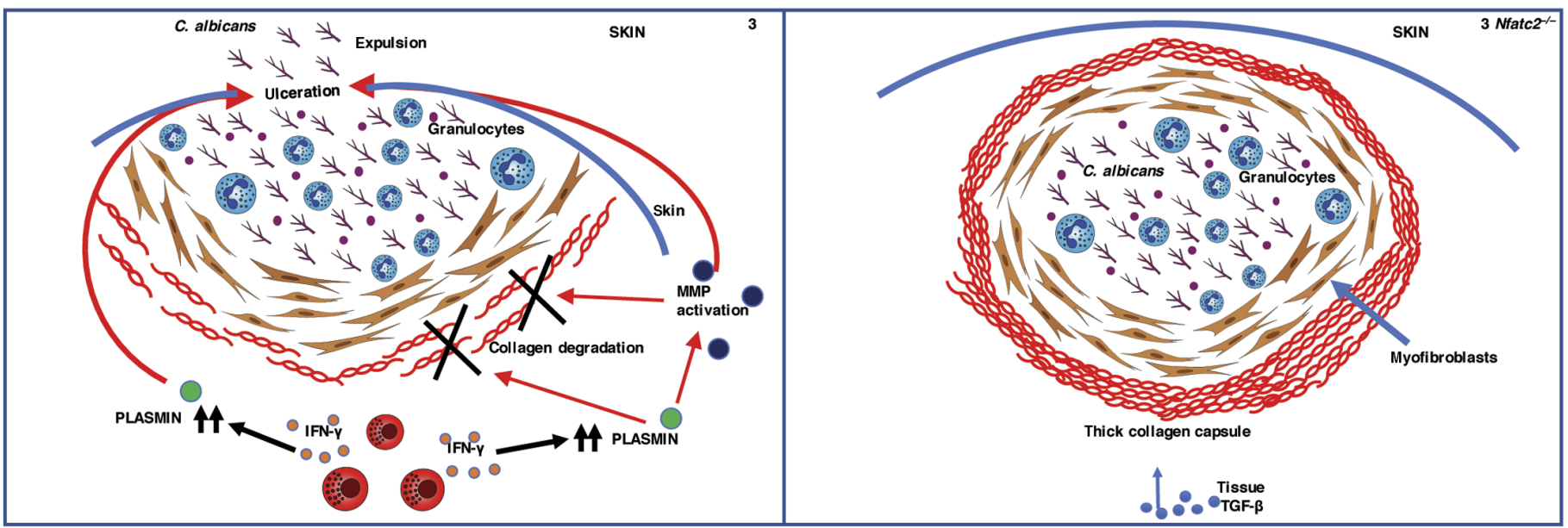

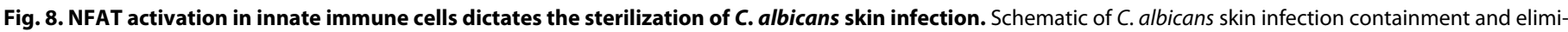
nation. Distinct phases can be identified in the inflammatory process that takes place after C. albicans skin infections. During the very early phases (1), granulocytes are recruited and form an abscess around the invading microorganisms to avoid infection spreading. The containment of the infection is ensured by fibroblasts that, once activated by TGF- $\beta$, proliferate and deposit collagen around the abscess to form a capsule. Later, IFN- $\gamma$, produced by NK cells activated in the draining lymph nodes (dLN), antagonizes TGF- $\beta$ and thus avoids excessive fibroblast activation and excessive collagen deposition and also avoids the differentiation of fibroblasts into myofibroblasts (2). Last, IFN- $\gamma$ ensures the activation of the fibrinolytic system and the consequent activation of metalloproteinases by plasmin (3). During the elimination phase, proteinases digest the collagen capsule and induce skin ulceration for the microbial expulsion out of the skin (3). NFATc2 activation in DCs after C. albicans exposure leads to IL-2 production. In turn, IL- 2 is required to elicit IFN- $\gamma$ release by NK cells (2). In the absence of NFATC2, IFN- $\gamma$ is not produced in sufficient amount to counteract the TGF- $\beta$ pathway $\left(2 \mathrm{Nfatc}^{--}\right)$and to induce the activation of the fibrinolytic system $\left(3 \mathrm{Nfatc2}{ }^{--}-\right.$); therefore, fibroblasts are hyperactive, deposit excessive collagen, and differentiate in myofibroblasts $\left(3 \mathrm{Nfatc}^{-/}{ }^{-}\right.$). This leads to the formation of a thick capsule that prevents skin ulceration and microbial expulsion out of the skin. 
form an organized abscess to control tissue damage and microbial spreading. The second phase leads to microbial elimination. This phase requires the activation of the fibrinolytic system that allows the discharge of microbes out of the skin. Upon infection, granulocytes are recruited to surround microbes, and active TGF- $\beta$ promotes a profibrotic response that favors the deposit of collagen around the abscess to improve microbial containment. The release of IFN- $\gamma$ in the skin by NK cells (previously activated in the lymph node by DCs) avoids excessive collagen deposition and the differentiation of fibroblasts into myofibroblasts, owing to the antagonistic effect of IFN- $\gamma$ on the TGF- $\beta$ pathway. IFN- $\gamma$ also favors plasmin generation by inducing the production of tPA. Plasmin activates the process of collagen capsule digestion, skin ulceration, and microbe discharge (Fig. 8). NFATc2 regulates IL-2 production by DCs after fungal encounter, and DC-derived IL-2 is required for eliciting IFN- $\gamma$ secretion by NK cells. In the absence of NFATc 2, IFN- $\gamma$ is not produced; therefore, the continuous signaling of TGF- $\beta$ and the consequent differentiation of fibroblasts into myofibroblasts, together with the limited activation of the fibrinolytic system, lead to the generation of a very thick capsule around the abscess. The thick capsule hampers skin ulceration and microbial elimination; thus, only the containment phase takes place.

The containment phase of the inflammatory process, although efficient, is an evolutionary primitive way to control the infections because a mechanical insult could be sufficient to break the containment and spread the infection. This type of infection control is probably reminiscent of ancient innate responses with microbial confinement via encapsulation and melanization (2). The appearance of the NFAT signaling pathway in evolution has eventually enabled the elimination phase favoring the interaction between the innate immune system and the fibrinolytic system.

From the pathogen side, the generation of plasmin has been described to favor microbial invasiveness by favoring extracellular matrix degradation (36). We show here that the fibrinolytic system can also help microbial elimination if activated in the correct time frame. The early activation of the TGF- $\beta$ pathway is likely to take place to also counteract the effects of premature plasmin generation.

The requirement of IL- 2 for IFN- $\gamma$ production and the requirement of IFN- $\gamma$ for plasmin activation and Candida eradication provide a molecular explanation for why some patients with chronic mucocutaneous candidiasis show C. albicans-specific defects in IL-2 and/or IFN- $\gamma$ production (37-40).

It is known that NFATc2 promotes $\mathrm{T}$ helper $1\left(\mathrm{~T}_{\mathrm{H}} 1\right)$ and suppresses $\mathrm{T}_{\mathrm{H}} 2$ responses (22). This has been attributed to the capacity of NFATc 2 to regulate IFN- $\gamma$ production by T cells (41). We show here that NK cells as well show a deficit of IFN- $\gamma$ production in NFATc2deficient mice. Diversely from T cells, the defect is not NK cellintrinsic but affects DCs.

A previous work demonstrates that human NK cells can be directly activated by $C$. albicans (42), whereas we show here that mouse NK cells do not respond directly to Candida but need the presence of DCs to acquire the effector functions necessary to fight the infection. Our data may seem to conflict with these findings or may suggest that human and mouse NK cells behave differently. Nevertheless, the discrepancy between the two works could only be ostensible. In the work by Hellwig et al. (42), NK cells are maintained in culture in the presence of IL-2, and we show that IL-2 is indeed fundamental to induce NK cell activation. Therefore, accessory cells could be required, also in humans, to provide an endogenous source of IL-2.

We showed that the absence of NFATc2 alters the levels of IFN- $\gamma$, and IFN- $\gamma$ is required for capsule digestion and microbial expulsion from skin. Nevertheless, we cannot exclude the fact that other molecular events regulated by NFATc2 contribute to the formation of encapsulated abscesses during skin fungal infections. For instance, it is known that cardiac expression of $\alpha$-SMA, which regulates the contractile activity of myofibroblasts, is induced by TGF- $\beta$ via the activation of the NFAT signaling pathway in both fibroblasts and mesangial cells $(43,44)$. Therefore, it is also possible that the absence of NFATc2 could (directly or indirectly via deregulation of other NFAT member activation) generate a spontaneous tendency of fibroblasts to proliferate and differentiate into myofibroblasts. Although we found here that NK cells are activated at the draining lymph node, we cannot exclude the fact that NK cell activation can occur in the skin as well.

In conclusion, our study evidences the importance of the fibrinolytic system for the eradication of skin infections. Moreover, this work shows previously unknown roles for TGF- $\beta$ and IFN- $\gamma$ during the inflammatory process induced by microorganisms in the skin. TGF- $\beta$ is mainly considered an anti-inflammatory cytokine that intervenes during the late phases of the inflammatory process to down-regulate inflammation and to start the resolution phase. In this study, it also emerges as a fundamental cytokine during the initial phases of the inflammatory response. By exerting its profibrotic functions, TGF- $\beta$ increases the effectiveness of the inflammatory process to avoid excessive microbial spreading in the tissue. Moreover, IFN- $\gamma$ contributes to microbial elimination not only by the induction of type 1 macrophages and neutrophils but also via the regulation of fibroblast functions (by antagonizing TGF- $\beta$ ) and the activation of the fibrinolytic system. IFN- $\gamma$-induced plasmin generation avoids excessive confinement of the infection (which obstructs microbial discharge) and allows microbial elimination that occurs not only via the phagocytic and antimicrobial activities of macrophages and neutrophils but also through direct microorganism elimination out of the ulcerated skin.

\section{MATERIALS AND METHODS Study design}

The overall objective of the study was to analyze the role of NFATc2 in the innate immune response to C. albicans and S. aureus infections of the skin. There was not a predefined study component. Mice were injected in the deep derma with C. albicans or S. aureus, and the inflammatory response in the skin was investigated by histology, Western blot and cytofluorimetric analyses, and qRT-PCR. The study was not blind. For each experiment, the number of biological replicates is indicated in the figure legend.

\section{Mouse strains}

All mice, housed under specific pathogen-free conditions, had been on a B6 background for at least 12 generations and were used at 7 to 12 weeks of age. WT C57BL/6 mice were supplied by Envigo, Italy. IFN- $\boldsymbol{\gamma}$-deficient mice were from the Jackson Laboratory. Rag ${ }^{-/-}$mice were from CNRS Centre de Distribution, Typage et Archivage animal in Orleans, France. CD11c.DOG mice were provided by N. Garbi (Institute of Molecular Medicine and Experimental Immunology, Bonn, Germany). In these mice, a specific DC ablation 
can be induced by DT injection. IL-2-deficient mice were provided by A. Schimpl (University of Würzburg, Würzburg, Germany) NFATc2deficient mice were provided by E. Serfling (University of Würzburg, Germany).

\section{C. albicans growth conditions and hyphal induction}

The C. albicans strain CAF3-1 (ura34::imm434/ura34::imm434), provided by W. A. Fonzi (Georgetown University), was routinely grown at $25^{\circ} \mathrm{C}$ in rich medium [YEPD (yeast extract, peptone, dextrose), $1 \%(\mathrm{w} / \mathrm{v})$ yeast extract, $2 \%(\mathrm{w} / \mathrm{v})$ Bacto Peptone, and 2\% (w/v) glucose] supplemented with uridine $(50 \mathrm{mg} / \mathrm{liter})$ as described. In this growth condition, cells showed a typical yeast morphology, and growth was monitored by counting the cell number using a Coulter CounterParticle Count and Size Analyser. Once cells reached a concentration of about $8 \times 10^{6}$ cells $/ \mathrm{ml}$, the total culture was harvested by centrifugation and resuspended in an equivalent volume of YEPDuridine medium buffered with Hepes $(50 \mathrm{mM}, \mathrm{pH}$ 7.5). Cells were incubated at $37^{\circ} \mathrm{C}$ for hyphal induction. Formation of hyphae was evaluated under a microscope at different time points following induction until its amount was assessed at $95 \%$.

\section{S. aureus}

S. aureus ATCC6538P cells were grown in LB medium (Difco) at $37^{\circ} \mathrm{C}$. For subcutaneous infections, stationary phase cultures were diluted to an optical density at $600 \mathrm{~nm}\left(\mathrm{OD}_{600}\right)$ of 0.05 and then grown until they reached an $\mathrm{OD}_{600}$ of 0.25 that corresponded approximately to $10^{6}$ colony-forming units $(\mathrm{CFU}) / \mathrm{ml}$. Cells were washed in phosphatebuffered saline, and appropriate dilutions were injected in mice.

\section{In vivo infections}

Mice were prepared by shaving the dorsal region at least 24 hours before injection. Mice were then injected in the deep derma with C. albicans hyphae $\left(5 \times 10^{6}\right.$ in a total volume of $\left.50 \mu \mathrm{l}\right)$ or $10^{6} \mathrm{CFU}$ of S. aureus in a final volume of $50 \mu \mathrm{l}$ in the shaved dorsal regions and macroscopically analyzed 1, 2, 3, and 7 days later for skin ulceration. In addition, infected skin was collected at different time points for histological and biochemical analyses.

In some experiments, recombinant IFN- $\gamma[1 \mu \mathrm{g}$ per mouse subcutaneously (sc); catalog no. 315-05, PeproTech] or LEAF purified anti-mouse IFN- $\gamma(50 \mu$ g per mouse sc; clone R4-6A2, catalog no. 505706; BioLegend) were co-injected together with C. albicans hyphae. LEAF purified rat immunoglobulin G1 $\kappa$ (IgG1 $\kappa$ ) (clone RTK2071, BioLegend) was used as isotype control (35 $\mu \mathrm{g}$ per mouse sc); SB-431542 (catalog no. 13031, Cayman Chemical) was used as TGF- $\beta$ inhibitor. It was injected daily intraperitoneally (ip) for 3 days, starting from day -1 (50 $\mu \mathrm{g}$ per mouse). For MMP-3 inhibition, MMP-3 inhibitor I was purchased from Calbiochem (catalog no. 444218) and injected sc together with C. albicans hyphae at a dosage of $125 \mu \mathrm{g}$ per mouse. The inhibitor was then reinjected 6 hours after infection (250 $\mu \mathrm{g}$ per mouse) intravenously (iv). Plasmin activation was blocked by injecting human PAI-1 ( $0.65 \mu \mathrm{g}$ per mouse) ( $25 \mu \mathrm{g}$; catalog no. A8111, Sigma-Aldrich) sc 6 hours before infection. Last, recombinant IL-2 (1 $\mu \mathrm{g}$ per mouse, 402-ML carrier-free, $\mathrm{R} \& \mathrm{D}$ Systems) was co-injected sc with C. albicans.

For NK cell depletion, mice received anti-asialo GM1 polyclonal antibodies (eBioscience, $30 \mu \mathrm{g}$ per mouse iv) at days $-3,-1$, and +1 . For DC depletion, DOG mice were treated with DT (Sigma-Aldrich, $16 \mathrm{ng} / \mathrm{g}$ ) sc and iv 4 hours before C. albicans infection. DT was readministered iv 48 hours later.

\section{Histopathology Immunohistochemistry}

Explanted skins were embedded in optimal cutting temperature freezing media (Bio-Optica). Sections $(5 \mu \mathrm{m})$ were cut on a cryostat, adhered to a Superfrost Plus slide (Thermo Scientific), fixed with acetone, and blocked with Normal Goat Serum (1:10) for $30 \mathrm{~min}$ at room temperature. Sections were then stained with primary antibody specific for $\alpha$-SMA (ab5694, Abcam), p-SMAD2/3 (clone D27F4, Cell Signaling), or IFN- $\gamma$ (XMG1.2, Thermo Scientific), 1 hour at room temperature. LEAF purified rat IgG1 $\kappa$ (clone RTK2071, BioLegend) was used as isotype control for IFN- $\gamma$ staining, whereas purified rabbit polyclonal IgG (BD Pharmingen) was used as isotype control for $\alpha$-SMA and p-SMAD2/3 (see fig. S26). Sections were washed with tris-buffered saline buffer, then labeled $30 \mathrm{~min}$ at room temperature with the Dako EnVision Anti-Rabbit System-HRP according to the manufacturer's recommendations, and counterstained with Meyer's hematoxylin solution (Bio-Optica). After dehydration, stained slides were mounted with Eukitt, and images were acquired with the NanoZoomer (Hamamatsu). Hematoxylin and eosin staining

Skin sections $(5 \mu \mathrm{m})$ were stained with Meyer's hematoxylin solution for $8 \mathrm{~min}$ and then washed in warm running tap water for $5 \mathrm{~min}$. Sections were stained with Eosin Y solution for $1 \mathrm{~min}$, washed in warm running tap water for $5 \mathrm{~min}$, rinsed in distilled water, and then dehydrated through passages in $95 \%$ and absolute alcohol. After dehydration, stained slides were cleared in xylene and mounted with Eukitt. Images were acquired with the NanoZoomer (Hamamatsu).

\section{PicroSirius Red staining}

Sections were stained with Meyer's hematoxylin solution for $8 \mathrm{~min}$ and then washed for $10 \mathrm{~min}$ in running tap water. Sections were stained in PicroSirius Red for 1 hour and then washed in two changes of acidified water. After dehydration in three changes of $100 \%$ ethanol, slides were cleared in xylene and mounted in Eukitt. Images were acquired with the NanoZoomer (Hamamatsu).

For collagen quantification, five fields (20x) from two sections per group were analyzed by separation into a red, green, and blue (RGB) filter, and the red area was mathematically divided by the RGB area and multiplied by $100 \%$. This calculation represents the percentage area staining positively for collagen fibers.

\section{Periodic acid-Schiff staining}

Sections were fixed with acetone for $1 \mathrm{~min}$ at room temperature and then washed for $1 \mathrm{~min}$ in slowly running tap water. Slides were rinsed in periodic acid solution for $5 \mathrm{~min}$ at room temperature. Slides were rinsed with several changes of distilled water and then with Schiff s reagent for $15 \mathrm{~min}$ at room temperature. After washing in running tap water, slides were counterstained in hematoxylin solution for $5 \mathrm{~min}$. Last, slides were dehydrated in three changes of 100\% ethanol, cleared in xylene, and mounted in Eukitt. Images were acquired with the NanoZoomer (Hamamatsu).

\section{Flow cytometry}

Intracellular staining was performed on lymph node single-cell suspension using Cytofix/Cytoperm reagents (BD Biosciences) according to the manufacturer's instructions. Single-cell suspensions were kept for 3 hours in the presence of brefeldin A $(10 \mu \mathrm{g} / \mathrm{ml}$; SigmaAldrich) before staining.

The antibodies used were as follows: phycoerythrin (PE)-antimouse CD49b (clone DX5, catalog no. 108908; BioLegend); allophycocyanin (APC)-anti-mouse IFN- $\gamma$ (clone XMG1.2, catalog no. 505810; BioLegend); fluorescein isothiocyanate (FITC)-anti-mouse 
CD3 (clone 17A2, (catalog no. 100204; BioLegend); APC-antimouse CD11b (clone M1/70, catalog no. 101212; BioLegend); PEanti-mouse CD11c (clone N418, catalog no. 117308; BioLegend); APC-anti-mouse CD11c (clone N418, catalog no. 117310; BioLegend); APC/Cy7-anti-mouse CD3 (clone 17A2, catalog no.100222; BioLegend); and peridinin chlorophyll protein-anti-mouse NK1.1 (clone PK136); Alexa 488-anti-mouse I-Ab antibody (clone AF\&-120.1); and PE-anti-mouse IL-2 (clone JES6-5H4) (all from BioLegend).

The antibodies used as isotype controls were as follows: PE mouse

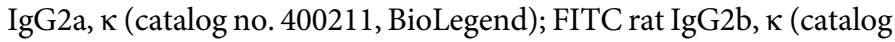
no. 400605, BioLegend); APC rat IgG1, к (catalog number 400411); $\mathrm{PE}$ rat IgG2b, $\kappa$ (catalog no. 400607, BioLegend); PE/Cy7 mouse IgG2a, א (catalog no. 400253, BioLegend); and APC/Cy7 Armenian hamster IgG (catalog no. 400927, BioLegend). NK cells were identified as $\mathrm{NK} 1.1^{+} \mathrm{CD}^{-}$lymphocytes. DCs were identified as $\mathrm{CD} 11 \mathrm{c}^{+} \mathrm{MHCII}^{+}$ cells. Samples were acquired with a Gallios flow cytometer (Beckman Coulter).

\section{Cells}

Bone marrow-derived dendritic cells (BMDCs) were generated by culturing bone marrow (BM) precursors, flushed from femurs, in Iscove's modified Dulbecco's medium (IMDM) (Euroclone) containing 10\% heat-inactivated fetal bovine serum (Euroclone), $100 \mathrm{IU}$ of penicillin, streptomycin $(100 \mu \mathrm{g} / \mathrm{ml}), 2 \mathrm{mM}$ L-glutamine (Euroclone), and granulocyte-macrophage colony-stimulating factor (CSF) (10 to $20 \mathrm{ng} / \mathrm{ml}$ ) for 8 days. BM-derived macrophages were cultured in IMDM containing $100 \mathrm{IU}$ of penicillin, streptomycin (100 $\mu \mathrm{g} / \mathrm{ml}), 2 \mathrm{mM}$ L-glutamine (all from Euroclone), and macrophage CSF (10 to $20 \mathrm{ng} / \mathrm{ml}$ ) for 10 days.

DCs for adoptive transfer experiments were expanded in vivo by transplanting mice with B16 tumor cells transduced with Flt3 ligand (FLT3L). Ten days after in vivo expansion, $\mathrm{CD} 11 \mathrm{c}^{+}$cells were purified from spleen by magnetic-activated cell sorting (MACS) by positive selection using CD11c microbeads (Miltenyi Biotec).

NK cells for in vitro experiments and for adoptive transfer experiments were purified from splenocytes (after red blood cell lysis) by MACS positive selection using CD49b (DX5) microbeads (Miltenyi Biotec). Purity was assessed by fluorescence-activated cell sorting (FACS) analysis and was routinely between 93 and $96 \%$.

Skin fibroblasts were isolated and differentiated from the ears of adult C57BL/6 WT and NFATc2-deficient mice. Mice were euthanized and ears were removed. The ears were then divided into two layers and cut into small pieces that were placed in a six-well tissue culture plate with $3 \mathrm{ml}$ of Dulbecco's modified Eagle's medium (catalog no. ECB7501L, Euroclone) containing 10\% heat-inactivated fetal bovine serum (catalog no. 10270, Gibco), 100 IU of penicillin, streptomycin $(100 \mu \mathrm{g} / \mathrm{ml}), 2 \mathrm{mM}$ L-glutamine (all from Euroclone), epidermal growth factor $(1 \mu \mathrm{g} / \mathrm{ml})$ (SRP3196, Sigma-Aldrich), and fibroblast growth factor $2(1 \mathrm{ng} / \mathrm{ml})$ (SRP4038, Sigma-Aldrich) for 1 week. After 1 week, adherent fibroblasts were detached with trypsin/EDTA (catalog no. ECB3001D, Euroclone) and grown in tissue culture plates. At $80 \%$ of confluence, cells were detached and divided by a ratio of 1:2 until passages 4 and 5 when they were used for experimental procedures.

\section{NK-DC cocultures}

BMDCs $\left(1 \times 10^{5}\right.$ per well $)$ and NK cells $\left(5 \times 10^{4}\right.$ per well for IFN- $\gamma$ release assays) were cocultured in flat-bottom 96-well plates in the presence or absence of $C$. albicans hyphae [multiplicity of infection (MOI), 0.005], and, where indicated, recombinant IL-2 (rIL-2) $(7.5 \mathrm{ng} / \mathrm{ml})$
(402-ML carrier-free, R\&D Systems), or purified rat anti-mouse IL-2 $(5 \mu \mathrm{g} / \mathrm{ml})$ (BD Biosciences) or purified rat IgG2a $(5 \mu \mathrm{g} / \mathrm{ml})$ (BD Biosciences) as isotype control. Two hours after stimulation, amphotericin B $(2.5 \mu \mathrm{g} / \mathrm{ml})$ (Sigma-Aldrich) was added to the cultures.

\section{TNF- $\alpha$, IL-2, IFN- $\gamma$, and IL-12 measurement}

Concentrations of IL-2, TNF- $\alpha$, IFN- $\gamma$, and IL-12 in supernatants were assessed by enzyme-linked immunosorbent assay (ELISA) kits purchased from BD OptEIA, eBioscience, and R\&D Systems, respectively.

\section{Quantitative reverse transcription polymerase chain reaction}

Pieces of lateral skin were homogenized in TRIzol reagent, and then RNA was extracted using Qiagen RNeasy Mini Kit (catalog no. 74104). Single-strand complementary DNA (cDNA) was synthesized using High-Capacity cDNA Reverse Transcription Kits (catalog no. 4368814, Applied Biosystems). The NanoDrop (Thermo Scientific) was used to titer mRNA, and amplification was performed using either the TaqMan Gene Expression Master Mix (catalog no. 4369016, Applied Biosystems) and TaqMan probes (Ifng, Mm01168134_m1; Fcer1a, Mm00438867_m1; SiglecF, Mm00523987_m1; Ly6c, Mm03009946_m1; Cd11c Mm00498698_m1; Nfatc1, Mm00479445_m1; Nfatc2, Mm01240677_m1; Nfatc3, Mm01249200_m1; 18S, Mm03928990_ g1;Gapdh, Mm99999915_g1) or the Power SYBR Green PCR Master Mix (Applied Biosystems) (Ly-6G: forward, 5' -TGGACTCTCACAGAAGCAAAG-3' and reverse, 5'-GCAGAGGTCTTCCTTCCAACA-3'; Gapdh: forward, 5' -CTGGCCAAGGTCATCCATG-3' and reverse, $5^{\prime}$-GCCATGCCAGTGAGCTTCC-3' $)$. Relative mRNA expression was calculated using the $\Delta \mathrm{C}_{\mathrm{t}}$ method, using either Gapdh or $18 S$ as a reference gene.

\section{Western blot}

Pieces of lateral skin were cut, put in Eppendorf tubes, and immersed in liquid nitrogen for snap freezing. Tissues were smashed and homogenized in $1 \mathrm{ml}$ of lysis buffer [ $50 \mathrm{mM}$ tris- $\mathrm{HCl}(\mathrm{pH} 7.4)$, $150 \mathrm{mM} \mathrm{NaCl}, 10 \%$ glycerol, and 1\% NP-40 supplemented with protease and phosphatase inhibitor cocktails; Roche] using a TissueLyser (full speed for $20 \mathrm{~min}$, Qiagen). Samples were then maintained in constant agitation for 2 hours at $4^{\circ} \mathrm{C}$ and centrifuged for $20 \mathrm{~min}$ at $13,000 \mathrm{~g}$ at $4^{\circ} \mathrm{C}$. The supernatants were collected into a new Falcon tube. Proteins were quantified using a bicinchoninic acid assay (Euroclone). Cell lysates $(150 \mu \mathrm{g})$ were run on a $10 \%$ polyacrylamide gel, and SDS-polyacrylamide gel electrophoresis was performed following standard procedures. After protein transfer, nitrocellulose membranes (Thermo Scientific) were incubated with the antibodies specific for phosphorylated SMAD2/3 (clone D27F4, Cell Signaling), mSerpin E1 (goat polyclonal IgG, R\&D Systems), tPA (rabbit polyclonal, NOVUS Biologicals), and $\beta$-actin (rabbit polyclonal, Cell Signaling) and developed using an enhanced chemiluminesence substrate reagent (Thermo Scientific).

\section{Plasmin and MMP-3 activity assays}

Pieces of lateral skin were cut, put in Eppendorf tubes, and immersed in liquid nitrogen for snap freezing. Tissues were smashed and homogenized in $1 \mathrm{ml}$ of an optimized buffer [150 $\mathrm{nM} \mathrm{NaCl}$, $1 \% \mathrm{NP}-40$, and $50 \mathrm{mM}$ tris- $\mathrm{HCl}$ (pH 8.0)] with a TissueLyser (Qiagen) (full speed for $20 \mathrm{~min}$ at $4^{\circ} \mathrm{C}$ ). Samples were then maintained in 
constant agitation for 2 hours at $4^{\circ} \mathrm{C}$ and centrifuged for $20 \mathrm{~min}$ at $13,000 \mathrm{~g}$ at $4^{\circ} \mathrm{C}$. Samples $(50 \mu \mathrm{l})$ were then used for plasmin measurement using the Plasmin Activity Assay Kit (Abcam) and for active MMP-3 measurement using the Activity Assay Kit (Abcam).

\section{Adoptive transfer experiments}

For the adoptive transfer of NK cells, WT or IFN- $\gamma$-deficient mice were injected iv with lipopolysaccharide (LPS) (2 mg LPS/gbw) to activate NK cells. Two hours and $30 \mathrm{~min}$ after activation, NK cells were purified from spleen and administered iv to NFATc2-deficient mice $\left(2 \times 10^{6}\right.$ per mouse) 4 hours after $C$. albicans infection.

For the experiments of DC adoptive transfer, DCs were purified form the spleen of WT, NFATc2-deficient, and IL-2-deficient mice. Purified DCs were then co-injected with C. albicans $\left(2 \times 10^{6}\right.$ per mouse). The same mice also received purified DCs by intravenous administration $\left(10^{6}\right.$ per mouse) after C. albicans infection.

\section{Statistical analysis}

Means were compared by either unpaired parametric $t$ tests or twoway analysis of variance (ANOVA). Data are expressed and plotted as means \pm squared deviations from the mean (SDM) or \pm SEM values. Sample sizes for each experimental condition are provided in the figure legends. $P$ values for Kaplan-Meier curves were calculated with log-rank test. All $P$ values were calculated using Prism (GraphPad). Differences were considered significant if $P \leq 0.05$.

\section{SUPPLEMENTARY MATERIALS}

immunology.sciencemag.org/cgi/content/full/2/15/eaan2725/DC1 Fig. S1. Expression of NFATc1, NFATC2, and NFATc3 in immune cells. Fig. S2. Magnifications of the selected areas shown in Fig. 1C. Fig. S3. Additional histological images of the abscess after $C$. albicans infection. Fig. S4. Histology of the abscess 1 month after infection of NFATc2-deficient mice. Fig. S5. Granulocyte and monocyte recruitment at the infection site of WT and NFATc2deficient mice.

Fig. S6. Visualization of $C$. albicans at the infection site 6 to 8 days after infection. Fig. S7. Additional histological images of $\alpha$-SMA staining in skin sections of WT and NFATc2-deficient mice.

Fig. S8. Additional histological images of $p-S M A D 2,3$ staining Fig. S9. Magnifications of the selected areas shown in Fig. 3D.

Fig. S10. Additional histological images of the abscesses after C. albicans infection in the presence of a TGF- $\beta$ inhibitor.

Fig. S11. Additional histological images of IFN- $\gamma$ staining

Fig. S12. IFN- $\gamma$ induces capsule digestion.

Fig. S13. Additional histological images of the abscesses after C. albicans infection in the presence of PAI-1.

Fig. S14. Inhibition of plasmin or MMP-3 interferes with C. albicans elimination.

Fig. S15. IFN- $\gamma$ mRNA is up-regulated in the infected skin of RAG-2-deficient mice.

Fig. S16. DCs are necessary for the activation of NK cells in the presence of C. albicans in vitro.

Fig. S17. DC depletion after DT injection in DOG mice.

Fig. S18. Granulocyte and monocyte recruitment at the infection site of DOG mice treated or not with DT to deplete DCs.

Fig. S19. Additional histological images of IFN- $\gamma$ staining in the infected skin of DOG mice.

Fig. S20. IL-12 production by BMDCs after C. albicans stimulation.

Fig. S21. Original Western blots shown in Fig. 3A.

Fig. S22. Original Western blots shown in Fig. 4 ( $E$ and F).

Fig. S23. Original Western blots shown in Fig. 5E.

Fig. S24. Original Western blots shown in Fig. 7C.

Fig. S25. Original Western blots shown in Fig. 7D.

Fig. S26. Representative isotype control stainings for immunohistochemical analyses.

Fig. S27. Gating strategies used in cytofluorimetric analyses.

Fig. S28. Representative isotype control stainings for cytofluorimetric analyses.

Raw data for Figs. 1 (B, D, and E), 4 ( $A, C$, and $G), 5$ ( $A, C, F, G, H$, and $J), 6$ (B to I), and $7 A$; and

figs. S1 ( $A$ and B), S5, S14, S15, S16, S17A, S18, and S20 (Microsoft Excel format).

\section{REFERENCES AND NOTES}

1. M. R. Müller, A. Rao, NFAT, immunity and cancer: A transcription factor comes of age. Nat. Rev. Immunol. 10, 645-656 (2010).

2. L.-M. Vanha-Aho, S. Valanne, M. Rämet, Cytokines in Drosophila immunity. Immunol. Lett. 170, 42-51 (2016).

3. H. Wu, A. Peisley, I. A. Graef, G. R. Crabtree, NFAT signaling and the invention of vertebrates. Trends Cell Biol. 17, 251-260 (2007).

4. I. Zanoni R. Ostuni, G. Capuano, M. Collini, M. Caccia, A. E. Ronchi, M. Rocchetti, F. Mingozzi, M. Foti, G. Chirico, B. Costa, A. Zaza, P. Ricciardi-Castagnoli, F. Granucci, CD14 regulates the dendritic cell life cycle after LPS exposure through NFAT activation. Nature 460, 264 (2009).

5. H. S. Goodridge, R. M. Simmons, D. M. Underhill, Dectin-1 stimulation by Candida albicans yeast or zymosan triggers NFAT activation in macrophages and dendritic cells. J. Immunol. 178, 3107-3115 (2007).

6. M. B. Greenblatt, A. Aliprantis, B. Hu, L. H. Glimcher, Calcineurin regulates innate antifungal immunity in neutrophils. J. Exp. Med. 207, 923-931 (2010).

7. S. Xu, J. Huo, K. G. Lee, T. Kurosaki, K. P. Lam, Phospholipase C $\gamma 2$ is critical for Dectin-1mediated $\mathrm{Ca} 2+$ flux and cytokine production in dendritic cells. J. Biol. Chem. 284, 7038 (2009).

8. D. Mourão-Sá, M. J. Robinson, S. Zelenay, D. Sancho, P. Chakravarty, R. Larsen, M. Plantinga, N. Van Rooijen, M. P. Soares, B. Lambrecht, C. Reis e Sousa, CLEC-2 signaling via Syk in myeloid cells can regulate inflammatory responses. Eur. J. Immunol. 41, 3040-3053 (2011).

9. T. Yamasaki, W. Ariyoshi, T. Okinaga, Y. Adachi, R. Hosokawa, S. Mochizuki, K. Sakurai, T. Nishihara, The dectin 1 agonist curdlan regulates osteoclastogenesis by inhibiting nuclear factor of activated T cells cytoplasmic 1 (NFATc1) through Syk kinase. J. Biol. Chem. 289, 19191-19203 (2014).

10. N. Perico, G. Remuzzi, Prevention of transplant rejection: Current treatment guidelines and future developments. Drugs 54, 533-570 (1997).

11. M. S. Deleuran, C. Vestergaard, Therapy of severe atopic dermatitis in adults. J. Dtsch. Dermatol. Ges. 10, 399-406 (2012).

12. E. Roekevisch, P. I. Spuls, D. Kuester, J. Limpens, J. Schmitt, Efficacy and safety of systemic treatments for moderate-to-severe atopic dermatitis: A systematic review. J. Allergy Clin. Immunol. 133, 429-438 (2014).

13. S. W. Kashem, B. Z. Igyarto, M. Gerami-Nejad, Y. Kumamoto, J. A. Mohammed, E. Jarrett, R. A. Drummond, S. M. Zurawski, G. Zurawski, J. Berman, A. Iwasaki, G. D. Brown, D. H. Kaplan, Candida albicans morphology and dendritic cell subsets determine Thelper cell differentiation. Immunity 42, 356-366 (2015).

14. J. A. Fishman, Infections in immunocompromised hosts and organ transplant recipients: Essentials. Liver Transpl. 17 (suppl. 3), S34-S37 (2011).

15. X.-m. Meng, D. J. Nikolic-Paterson, H. Y. Lan, TGF- $\beta$ : The master regulator of fibrosis. Nat. Rev. Nephrol. 12, 325-338 (2016).

16. N. Khalil, TGF- $\beta$ : From latent to active. Microbes Infect. 1, 1255-1263 (1999).

17. M. A. Travis, D. Sheppard, TGF- $\beta$ activation and function in immunity. Annu. Rev. Immunol. 32, 51-82 (2014)

18. A. W. Taylor, Review of the activation of TGF- $\beta$ in immunity. J. Leukoc. Biol. 85, 29-33 (2009).

19. X. Dong, B. Zhao, R. E. lacob, J. Zhu, A. C. Koksal, C. Lu, J. R. Engen, T. A. Springer, Force interacts with macromolecular structure in activation of TGF- $\beta$. Nature 542, 55-59 (2017).

20. L. Ulloa, J. Doody, J. Massagué, Inhibition of transforming growth factor- $\beta / S M A D$ signalling by the interferon- $\gamma /$ STAT pathway. Nature 397, 710-713 (1999).

21. O. Eickelberg, A. Pansky, E. Koehler, M. Bihl, M. Tamm, P. Hildebrand, A. P. Perruchoud, M. Kashgarian, M. Roth, Molecular mechanisms of TGF- $\beta$ antagonism by interferon $\gamma$ and cyclosporine A in lung fibroblasts. FASEB J. 15, 797-806 (2001).

22. K. J. Erb, T. Twardzik, A. Palmetshofer, G. Wohlleben, U. Tatsch, E. Serfling, Mice deficient in nuclear factor of activated T-cell transcription factor $\mathrm{c} 2$ mount increased Th2 responses after infection with Nippostrongylus brasiliensis and decreased Th1 responses after mycobacterial infection. Infect. Immun. 71, 6641-6647 (2003).

23. N. Ramos-DeSimone, E. Hahn-Dantona, J. Sipley, H. Nagase, D. L. French, J. P. Quigley, Activation of matrix metalloproteinase-9 (MMP-9) via a converging plasmin/ stromelysin-1 cascade enhances tumor cell invasion. J. Biol. Chem. 274, 13066-13076 (1999).

24. G. E. Davis, K. A. Pintar Allen, R. Salazar, S. A. Maxwell, Matrix metalloproteinase-1 and -9 activation by plasmin regulates a novel endothelial cell-mediated mechanism of collagen gel contraction and capillary tube regression in three-dimensional collagen matrices. J. Cell Sci. 114, 917-930 (2001).

25. S. Monea, K. Lehti, J. Keski-Oja, P. Mignatti, Plasmin activates pro-matrix metalloproteinase-2 with a membrane-type 1 matrix metalloproteinase-dependent mechanism. J. Cell. Physiol. 192, 160-170 (2002).

26. D. M. Dupont, J. B. Madsen, T. Kristensen, J. S. Bodker, G. E. Blouse, T. Wind, P. A. Andreasen, Biochemical properties of plasminogen activator inhibitor-1. Front. Biosci. (Landmark Ed.) 14, 1337-1361 (2009). 
27. H. R. Lijnen, Plasmin and matrix metalloproteinases in vascular remodeling. Thromb. Haemost. 86, 324-333 (2001).

28. K. Hochweller, J. Striegler, G. J. Hämmerling, N. Garbi, A novel CD11 1c.DTR transgenic mouse for depletion of dendritic cells reveals their requirement for homeostatic proliferation of natural killer cells. Eur. J. Immunol. 38, 2776-2783 (2008).

29. I. Zanoni, R. Ostuni, S. Barresi, M. Di Gioia, A. Broggi, B. Costa, R. Marzi, F. Granucci, CD14 and NFAT mediate lipopolysaccharide-induced skin edema formation in mice. J. Clin. Invest. 122, 1747-1757 (2012).

30. I. Zanoni, R. Spreafico, C. Bodio, M. Di Gioia, C. Cigni, A. Broggi, T. Gorletta, M. Caccia, G. Chirico, L. Sironi, M. Collini, M. P. Colombo, N. Garbi, F. Granucci, IL-15 cis presentation is required for optimal NK cell activation in lipopolysaccharide-mediated inflammatory conditions. Cell Rep. 4, 1235-1249 (2013).

31. F. Mingozzi, R. Spreafico, T. Gorletta, C. Cigni, M. Di Gioia, M. Caccia, L. Sironi, M. Collini, M. Soncini, M. Rusconi, U. H. von Andrian, G. Chirico, I. Zanoni, F. Granucci, Prolonged contact with dendritic cells turns lymph node-resident NK cells into anti-tumor effectors. EMBO Mol. Med. 8, 1039-1051 (2016).

32. N. C. Rogers, E. C. Slack, A. D. Edwards, M. A. Nolte, O. Schulz, E. Schweighoffer, D. L. Williams, S. Gordon, V. L. Tybulewicz, G. D. Brown, C. Reis e Sousa, Syk-dependent cytokine induction by Dectin-1 reveals a novel pattern recognition pathway for $C$ type lectins. Immunity 22, 507-517 (2005).

33. T. Zelante, A. Y. W. Wong, T. J. Ping, J. Chen, H. R. Sumatoh, E. Viganò, Y. Hong Bing, B. Lee, F. Zolezzi, J. Fric, E. W. Newell, A. Mortellaro, M. Poidinger, P. Puccetti, P. Ricciardi-Castagnoli, $\mathrm{CD}_{103^{+}}$dendritic cells control Th17 cell function in the lung. Cell Rep. 12, 1789-1801 (2015).

34. O. Boyman, J. Sprent, The role of interleukin-2 during homeostasis and activation of the immune system. Nat. Rev. Immunol. 12, 180-190 (2012).

35. F. Granucci, I. Zanoni, N. Pavelka, S. L. H. van Dommelen, C. E. Andoniou, F. Belardelli, M. A. Degli Esposti, P. Ricciardi-Castagnoli, A contribution of mouse dendritic cell-derived IL-2 for NK cell activation. J. Exp. Med. 200, 287-295 (2004).

36. S. Bergmann, S. Hammerschmidt, Fibrinolysis and host response in bacterial infections. Thromb. Haemost. 98, 512-520 (2007).

37. F. L. van de Veerdonk, T. S. Plantinga, A. Hoischen, S. P. Smeekens, L. A. B. Joosten, C. Gilissen, P. Arts, D. C. Rosentul, A. J. Carmichael, C. A. A. Smits-van der Graaf, B. J. Kullberg, J. W. M. van der Meer, D. Lilic, J. A. Veltman, M. G. Netea, STAT1 mutations in autosomal dominant chronic mucocutaneous candidiasis. N. Engl. J. Med. 365, 54-61 (2011).

38. K. Eyerich, S. Rombold, S. Foerster, H. Behrendt, H. Hofmann, J. Ring, C. Traidl-Hoffmann, Altered, but not diminished specific T cell response in chronic mucocutaneous candidiasis patients. Arch. Dermatol. Res. 299, 475-481 (2007).

39. D. de Moraes-Vasconcelos, N. M. Orii, C. C. Romano, R. Y. Iqueoka, A. J. D. S. Duarte, Characterization of the cellular immune function of patients with chronic mucocutaneous candidiasis. Clin. Exp. Immunol. 123, 247-253 (2001).

40. D. Lilic, I. Gravenor, N. Robson, D. A. Lammas, P. Drysdale, J. E. Calvert, A. J. Cant, M. Abinun, Deregulated production of protective cytokines in response to Candida albicans infection in patients with chronic mucocutaneous candidiasis. Infect. Immun. 71, 5690-5699 (2003).
41. A. Kiani, F. J. García-Cózar, I. Habermann, S. Laforsch, T. Aebischer, G. Ehninger, A. Rao, Regulation of interferon- $\gamma$ gene expression by nuclear factor of activated T cells. Blood 98, 1480-1488 (2001).

42. D. Hellwig, J. Voigt, M. Bouzani, J. Löffler, D. Albrecht-Eckardt, M. Weber, S. Brunke, R. Martin, O. Kurzai, K. Hünniger, Candida albicans induces metabolic reprogramming in human NK cells and responds to perforin with a zinc depletion response. Front. Microbiol. 7, 750 (2016).

43. S. L. Cobbs, J. L. Gooch, NFATC is required for TGF $\beta$-mediated transcriptional regulation of fibronectin. Biochem. Biophys. Res. Commun. 362, 288-294 (2007).

44. K. M. Herum, I. G. Lunde, B. Skrbic, G. Florholmen, D. Behmen, I. Sjaastad, C. R. Carlson, M. F. Gomez, G. Christensen, Syndecan-4 signaling via NFAT regulates extracellular matrix production and cardiac myofibroblast differentiation in response to mechanical stress. J. Mol. Cell. Cardiol. 54, 73-81 (2013).

Acknowledgments: CD11c.DOG mice were provided by N. Garbi (Institute of Molecular Medicine and Experimental Immunology, Bonn, Germany). IL-2-deficient mice were provided by A. Schimpl (University of Würzburg, Würzburg, Germany), and NFATc2-deficient mice were provided by E. Serfling (University of Würzburg, Germany). Funding: I.Z. is supported by NIH grants 1R01Al121066-01A1 and 1R01DK115217, HDDC (Harvard Digestive Diseases Center) P30 DK034854 grant, the Harvard Medical School Milton Fund, the CCFA (Crohn's \& Colitis Foundation) Senior Research Award, the Eleanor and Miles Shore 50th Anniversary Fellowship Program, and the Cariplo Foundation. F.G. is supported by the Associazione Italiana per la Ricerca sul Cancro (IG 2016ld.18842), the Cariplo Foundation (grant 2014-0655), and the Fondazione Regionale per la Ricerca Biomedica. G.S. is supported by fellowships from SYSBIONET, the Italian roadmap of the European Strategy Forum on Research Infrastructures. Author contributions: W.S. performed and participated in most of the experiments and performed statistical analyses; S.B. performed Western blot analyses and participated in the infection experiments; F.M. performed the infection experiments and the histological analyses; A.B. performed FACS analyses; I.O., G.S., and M.V. provided C. albicans for each infection experiment and provided expertise in fungal handling; M.V. also contributed to data interpretation; J.R.K. and N.L. provided C. albicans expressing green fluorescent protein and provided advice on C. albicans infections; A.P. and A. M.M. provided S. aureus; I.Z. and F.G. ideated the study and designed the experiments; and F.G. supervised the study and wrote the paper. Competing interests: The authors declare that they have no competing interests.

Submitted 21 March 2017

Resubmitted 21 June 2017

Accepted 27 July 2017

Published 22 September 2017

10.1126/sciimmunol.aan2725

Citation: W. Santus, S. Barresi, F. Mingozzi, A. Broggi, I. Orlandi, G. Stamerra, M. Vai, A. M. Martorana, A. Polissi, J. R. Köhler, N. Liu, I. Zanoni, F. Granucci, Skin infections are eliminated by cooperation of the fibrinolytic and innate immune systems. Sci. Immunol. 2, eaan2725 (2017). 


\section{ScienceImmunology}

\section{Skin infections are eliminated by cooperation of the fibrinolytic and innate immune systems}

William Santus, Simona Barresi, Francesca Mingozzi, Achille Broggi, Ivan Orlandi, Giulia Stamerra, Marina Vai, Alessandra M. Martorana, Alessandra Polissi, Julia R. Köhler, Ningning Liu, Ivan Zanoni and Francesca Granucci

Sci. Immunol. 2, eaan2725.

DOI: $10.1126 /$ sciimmunol.aan2725

\section{There's more than one way to skin an infection}

There are two phases of innate immune control of skin infection by Candida albicans--protective containment and elimination. Now, Santus et al. report that early activation of the transcript factor nuclear factor of activated T cells (NFAT) balances these two phases. During the containment phase, NFAT regulates active TGF- $\beta$ expression, which induces collagen deposition and traps the microbe. During the elimination phase, NFAT induces IFN- $\gamma$ that promotes skin ulceration and microbial expulsion. These functions are not restricted to Candida because cross-talk between the innate immune and fibrinolytic responses also contributed to defense against Staphylococcus aureus. This cooperation is critical to minimizing tissue damage while fighting infection.

ARTICLE TOOLS

SUPPLEMENTARY MATERIALS

REFERENCES

PERMISSIONS http://immunology.sciencemag.org/content/2/15/eaan2725

http://immunology.sciencemag.org/content/suppl/2017/09/19/2.15.eaan2725.DC1

This article cites 44 articles, 11 of which you can access for free http://immunology.sciencemag.org/content/2/15/eaan2725\#BIBL

http://www.sciencemag.org/help/reprints-and-permissions

Use of this article is subject to the Terms of Service

Science Immunology (ISSN 2470-9468) is published by the American Association for the Advancement of Science, 1200 New York Avenue NW, Washington, DC 20005. The title Science Immunology is a registered trademark of AAAS.

Copyright $@ 2017$ The Authors, some rights reserved; exclusive licensee American Association for the Advancement of Science. No claim to original U.S. Government Works 